\title{
THE USE OF EDUCATIONAL TECHNOLOGY IN THE LIGHT OF INTERNATIONAL STANDARDS AS A REFERENCE TO MEASURE THE EFFECTIVENESS OF USING THE EDUCATIONAL PROCESS
}

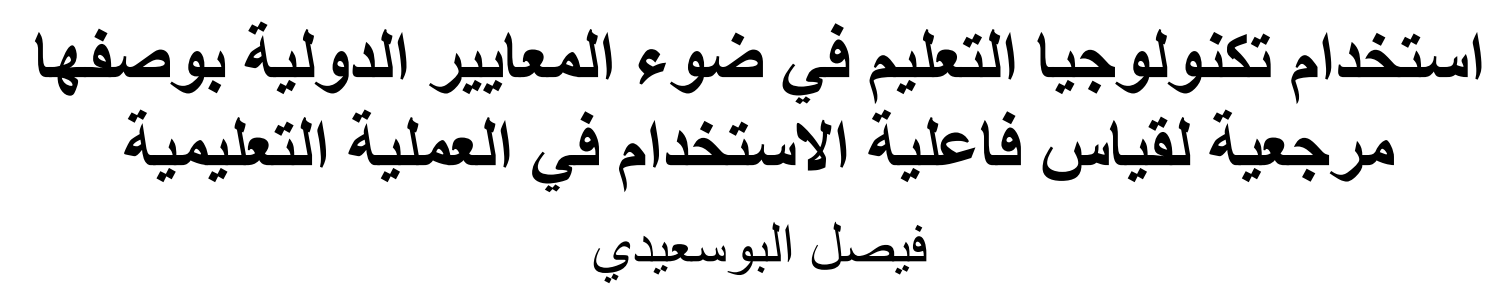

Faisal Ali Nasser Albusaidi ${ }^{1 \star}$ \& Prof. Dr, Muhammad Sabri Sahrir ${ }^{2}$

${ }^{1}$ Ph.D. Candidate at the Faculty of Education, International Islamic University Malaysia (IIUM); f@moe.om

${ }^{2}$ Prof. Dr. at the Faculty of Education, International Islamic University Malaysia (IIUM); muhdsabri@iium.edu.my

${ }^{*}$ Corresponding Author

\begin{abstract}
This descriptive, analytical study reviews the most important aspects related to measuring the effectiveness of the educational technology used based on international standards for using educational technology, as one of the important benchmarks for building on its educational dimensions and measuring the effectiveness of the use of educational technology. The problem lies in the lack of national standards that can be relied upon in many educational systems in educational institutions to measure the effectiveness of the use of educational technology, as well as the lack of adoption of building national standards on which to base the empowerment of education personnel in the use of educational technology. The study aims to introduce the dimensions of educational technology, its role in the teaching and learning process, and to define international standards for the use of educational technology related to teachers, students or educational leaders. Through the descriptive analytical approach, the study reached several results, the most important of which are: the components of educational technology greatly influence the improvement of the educational process and raise the level of quality in achieving educational goals. Information and communication in education.
\end{abstract}

Keywords: educational technology, international standards, scientific criteria, educational quality.

الملخص

تستعرض هذه الدر اسة الوصفية التحليلية أهم الجوانب المتصلة بقياس فاعليـة استخدام تكنولوجيـا التعليم المستندة إلى المعايير الدولية لاستخدام تكنولوجيا التعليم، بوصفها الحهد أحد المحكات المرجعيـة المهمة التي يمكن البناء على أبعادها التربوية وقياس مدى فاعلية استخدام تكنولوجيـا التعليم. تكمن 
المشكلة في عدم وجود معابير وطنية يمكن الاستناد عليها في العديد من النظم التعليمية بمؤسسـات

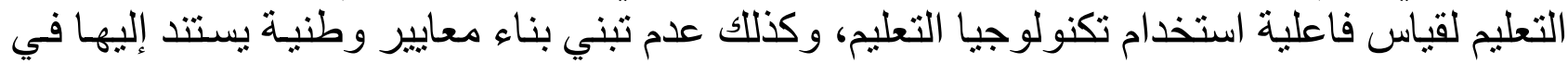

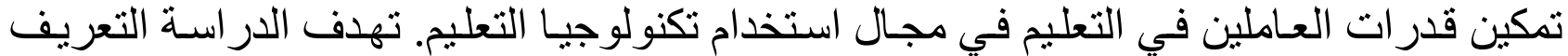

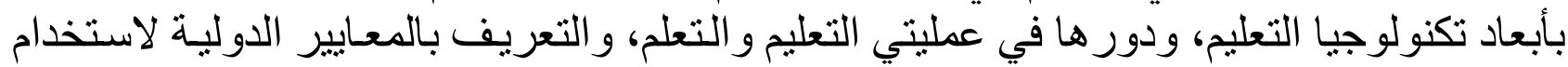

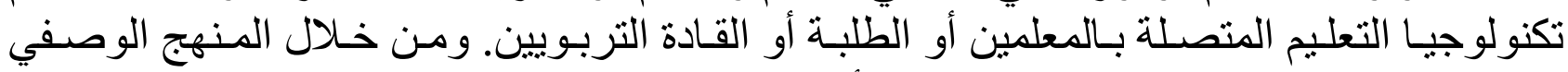
التحليلي توصلت الدر اسة إلى نتائج عدة من أبرز ها: تؤثر مكونات تكنولوجيا التعليم بصورة كبيـيرة

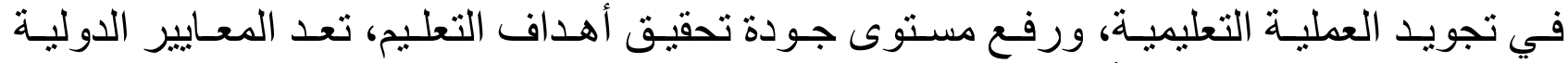

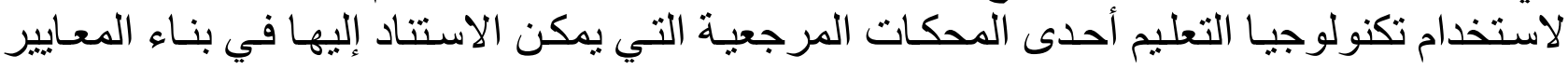
الوطنية لاستخدام تكنولوجيا المعلومات و الاتصالات في التعليم. كلمات مفتاحية: تكنولوجيا التعليم، المعايير الدولية، المحكات العلمية، الجودة التعليمية.

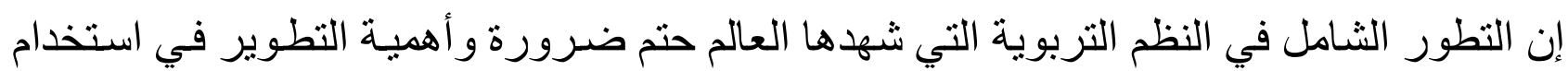

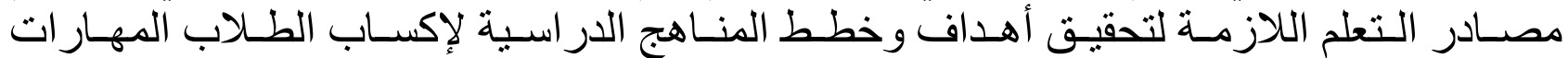

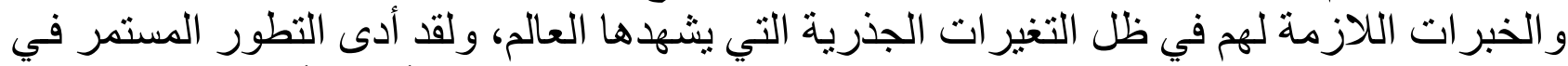

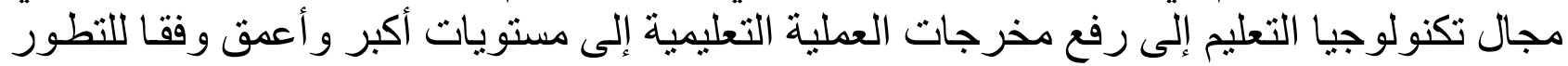

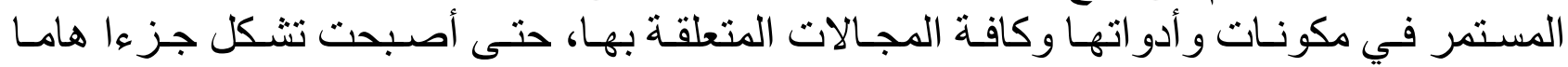
وجو هريا في عملية التعليم و التعلم لا يمكن الاستغناء عنها إنها الطلاقا.

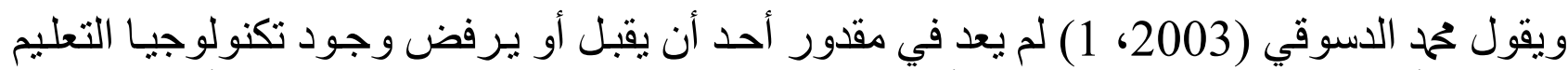

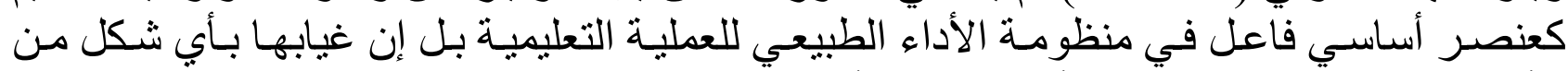

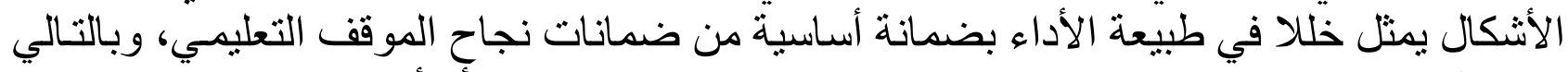

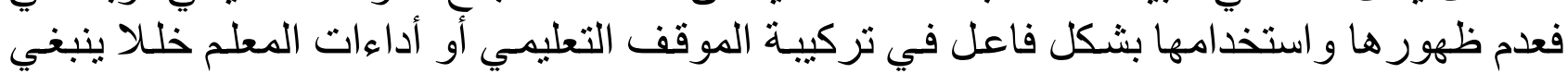

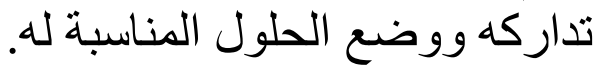

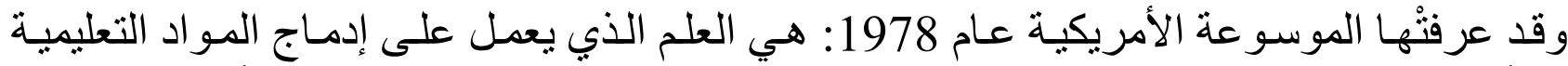

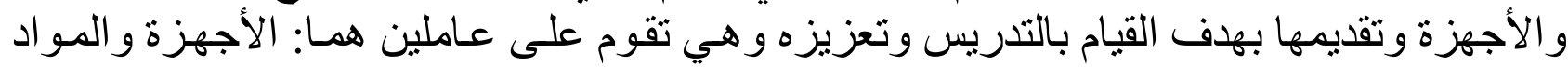
التعليمية التي تتمل البرمجيات و الصور وذللك لتحقيق الأهداف التعليمية.

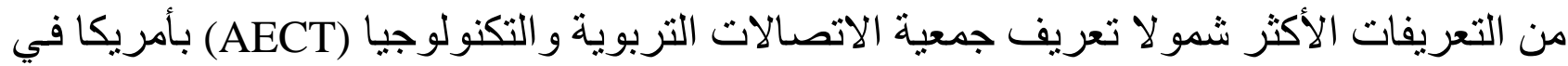

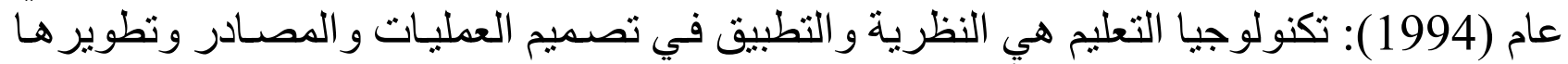

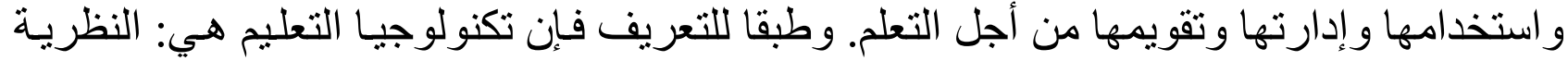

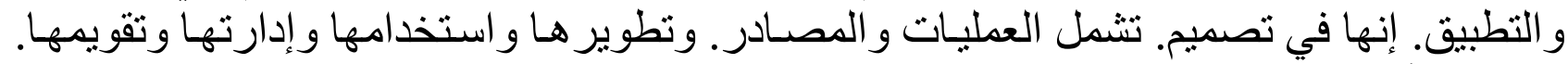
وهي من أجل التعلم.

ويؤكد هنا مصطفى عبد السميع (2005) على أن تكنولوجيا التعليم ليست فقط استخدام الأسـاليب الحديثة في العملية التربوية أو استخدام الآلات و الأجهزة التعليمية و إنما طريقة تفكير تنبثق من بني 
و مفـاهيم ونظريـات ومهـار ات تدريس ووسـائل تكنولوجيـا التعليم لا تعني فقط الحاسبات ووسـائل

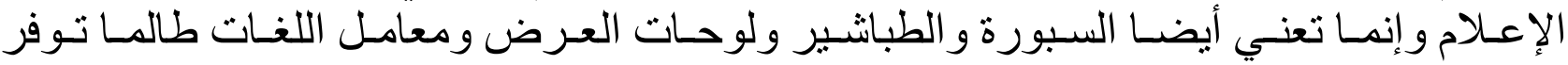
الاستخدام الجيد و التوقيت المناسب لما تتطلبه العملية التربوية.

مشكلة الدراسة: ماسة:

في ظل حرص مختلف النظم التعليمية على المستوى العالمي نحو تمكين استخدام تكنولوجيا التعليم في العملية التعليمية وتوفير العديد من المتطلبات و الإمكانيات اللازمة لها داخل المدارس إلا أن هنالك عدد من جوانب الخلل التي يجب الوقوف عليها و الخاصة في جو هر الاستخدام ذات الصلة بفاعلية استخدامها ودور ها في تحقيق وتجويد التعليم، ويمكن الإشارة إليها على النحو التالي: ـ لا تمتلك العديد من النظم التعليمية معابير وطنية تم بناءها بالاستتاد إلى معايير دولية حول استخدام تكنولوجيا التعليم داخل المدارس، وتعني بمختلف شر ائح العملية التعليمية، بحيث يتم بناء خطط واستر اتيجيات التطوير المتصلة بهذا الجانب بالترابط مع هذه المعابير الوطنية بصورة مستمرة.

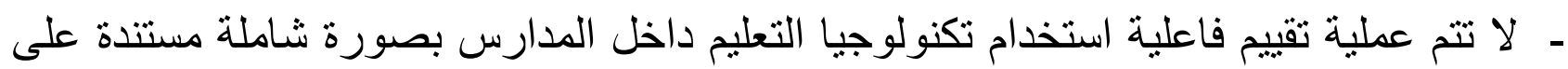

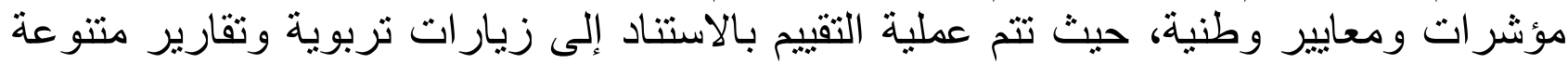
عامة، حيث لا توجد مؤشرات دقيقة يمكن أن تكشف بعض وضن جوانب الخلل العميقة في استخدام تكنولوجيا التعليم، و هذا يتطلب وجود معايير يمكن الركون إليها في عملية التقييم، ووجود فرق عمل متخصصة في هذا التقييم.

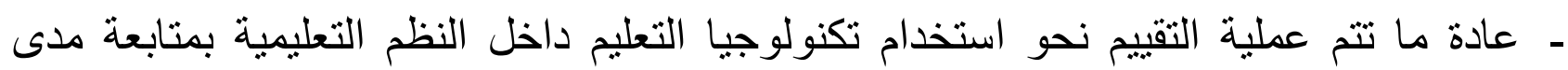
تطبيق المعلم لهذه التكنولوجيا فقط، و إغفال تقييم فئات أخرى في هذا المجال مثل الطلبة أو القادة

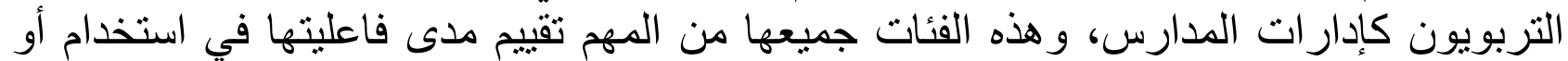
تمكين إرساء وتوظيف تكنولوجيا التعليم داخل المدارس نظر التكاملية الدور في هذا الجانب بثكل

و اضنح.

ـ ل التبنى بر امج التدريب الخاصة بالمعلمين خاصة إلى معايير وطنية حيث ثتم عملية التدريب بالاستناد إلى بعض الكفايات المطلوبة للمعلمين في ضوء التقارير العامة أو الزيار ات الميدانية لتنفيذ الموقف التعليمي، و هذا غير كافي لكون أن الأمر يتطلب وجود دعابير وطنية وكفايات شاملة خاصة بالمعلمين خاصة بحيث يتم بناء بر امج التدريب بالاستتاد إلى معايير وكفايات متصلة بهونة بهذا

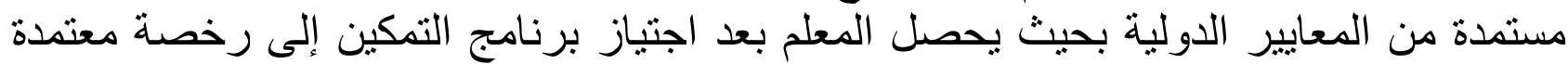

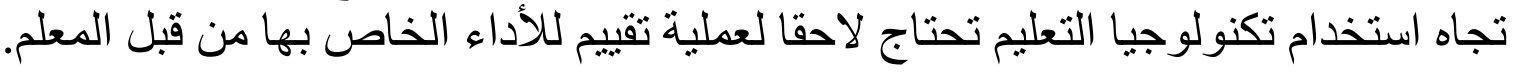
لهذا تأتي هذه الدراسة نحو معالجة هذه المشكلات و التحديات ووضع الأسس اللازمة لها و التي يمكن تتفيذها وفقا لخطو ات محددة مستندة إلى معابير دولية في هذا المجال.

أهداف الدراسة:

أ. بيان أهمية تكنولوجيا التعليم في عمليتي التعليم و التعلم. ب. مناقثة دور تكنولوجيا التعليم و النموذج التربوي التكنولوجي المعاصر. ت. تحليل المعايير الدولية لاستخدام تكنولوجيا التعليم في العملية التعليمية. 


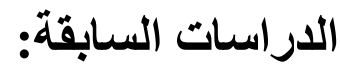

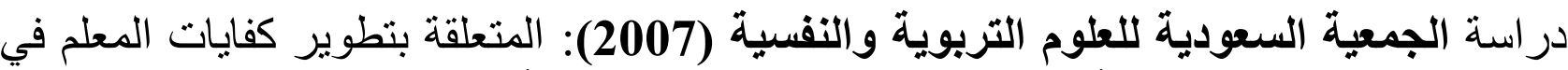

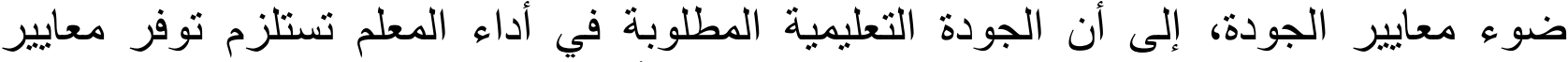

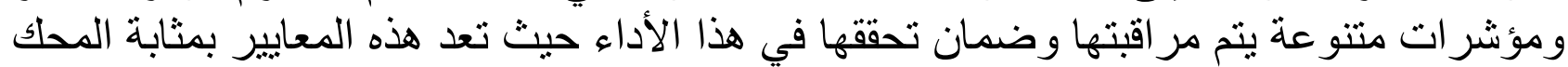

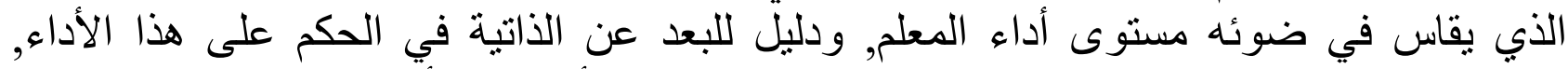

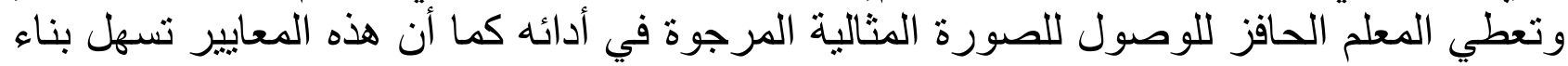

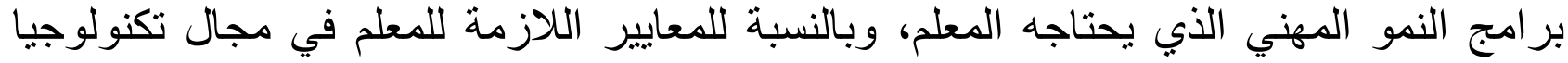
التعليم فإنه يمكن تحديدها في الجو النب التبالية:

- القدرة على تقديم الأنشطة الصفية واللاصفية باستخدام أساليب متنوعة معززة بتكنولوجيا التعليه. - مر اعاة التتوع في استخدام أدوات تكنولوجيا التعليم التي تمكن من تحقيق الأهداف التعليمية المنشودة.

ـ ـ التخطيط لاستخدام تكنولوجيا التعليم من قبل المعلم لتنفيذ الموقف التعليمي داخل المدرسة.

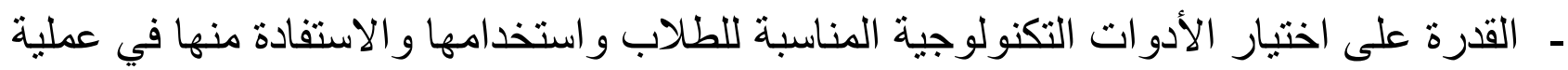
التعلم. - تتيح له التغلب على مشكلة جمود المحتوى الدراسي وعرض مادته التعليمية بصورة أكثر فاعلية. - توفر خدمات تعليمية أفضل, و إتاحة وقتاً أطول لطلابه واكتشاف مواهبهم، والتعرف على قدر اتهم.

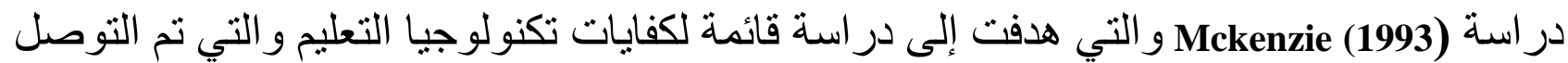

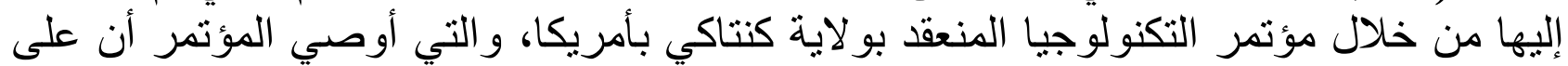

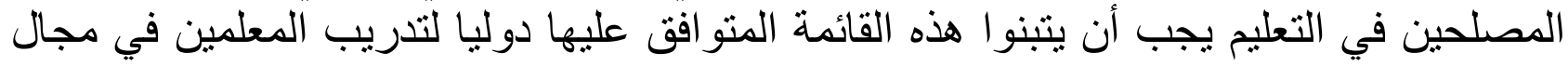

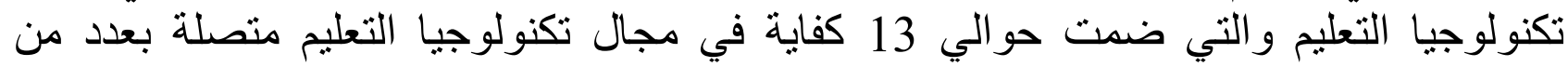

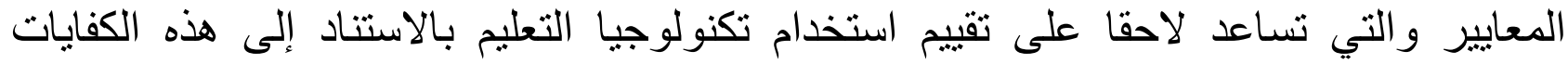
الو اضحة و المحددة و التي تم تمكينها لدى المعلمين.

دراسة عبد الرحمن المشيقح (1997) إلى معرفة أبرز المشكلات التي تحول دون التهات استخدام

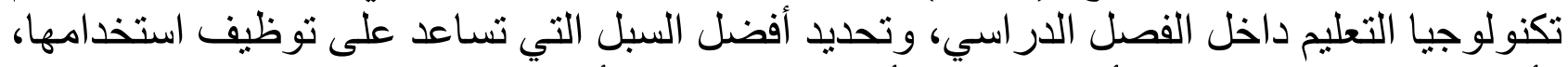

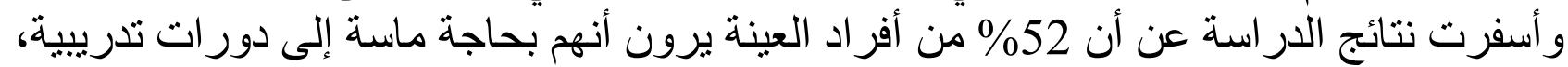

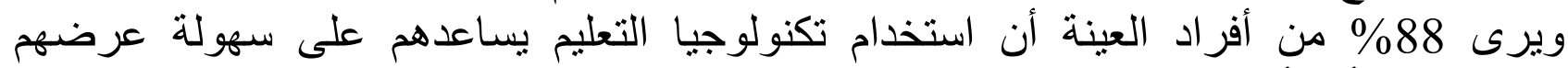

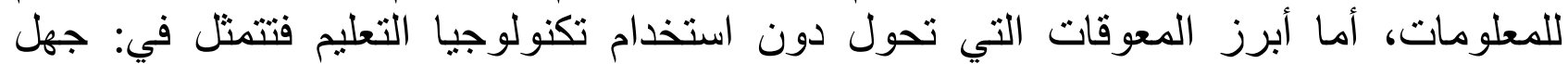

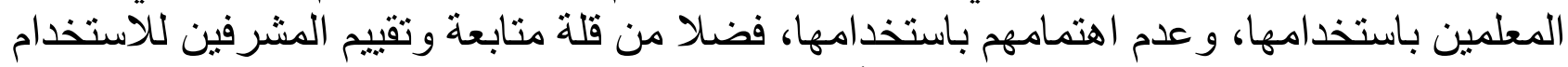

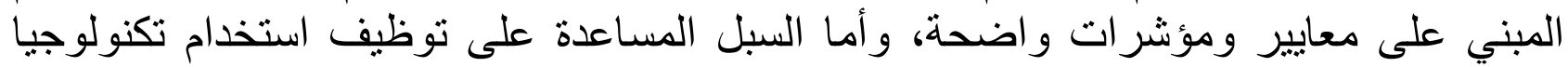

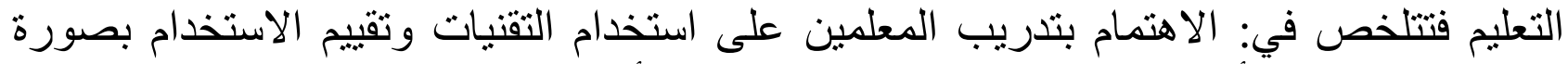

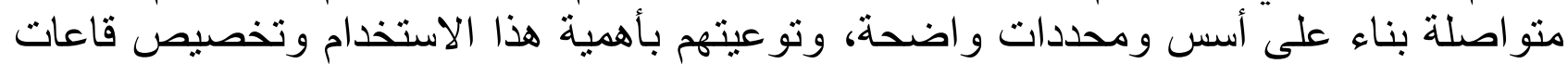

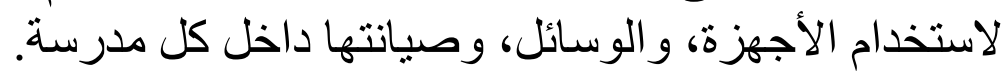




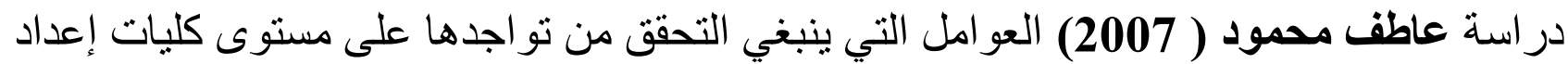

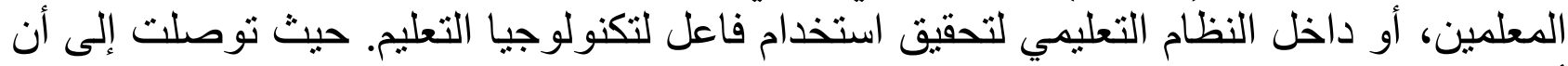

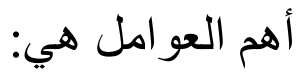

- ـ الروئة المشتركة: تتسم بالقيادة الإيجابية و الدعم الإداري من النظام التعليمي بالكامل.

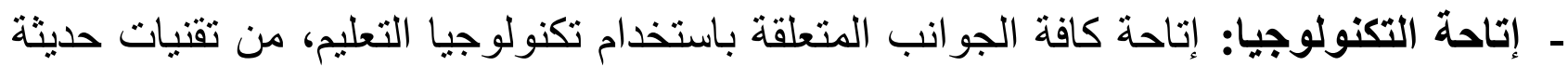

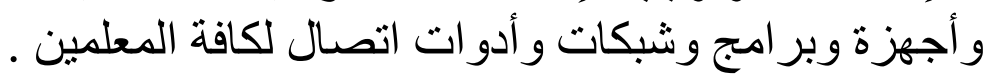

- مهارات المعلم: يمتلاك المعلمون مهار ات توظيف التكنولوجيا مبنية على كفايات و اضحة.

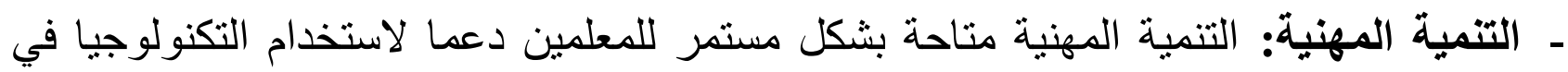
عمليتي التعليم و التعلم بالاستناد إلى معايير الاستخدام.

- الدعم القني: أن يتاح للمدارس الحفاظ على استمر ارية تفعيل التكنولوجيا في العملية التعليمية.

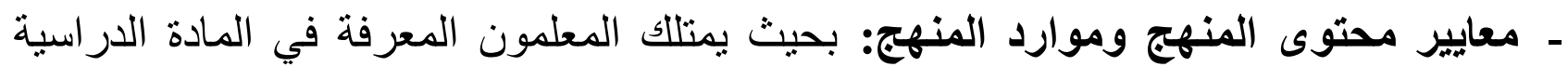

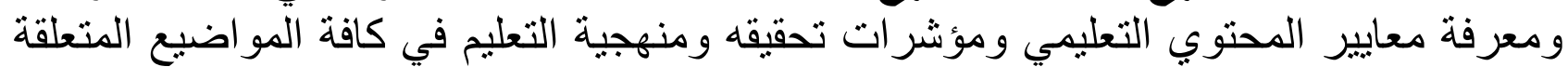

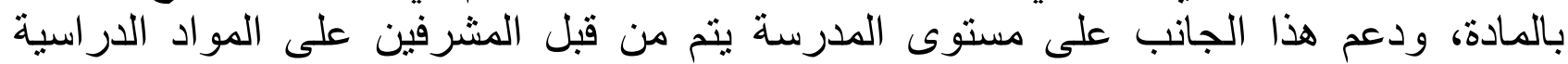
بالإدارة التعليمية .

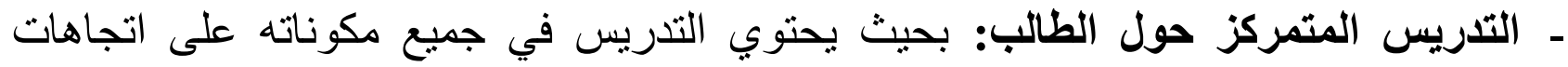

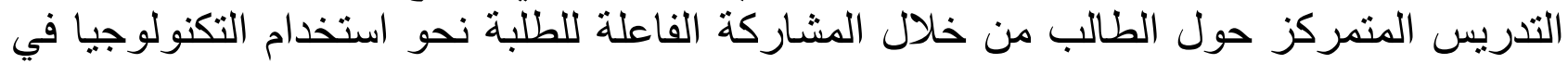
العملية التعليمية. فلا يقتصر استخدام التكنولوجيا على بعد المعلم و إنما على بعد الطالب بلى بصورة أساسية.

- التقييم: على أن يكون هناك تقييم مستمر لفعالية استخدام تكنولوجيا التعليم ولكافة المجالات

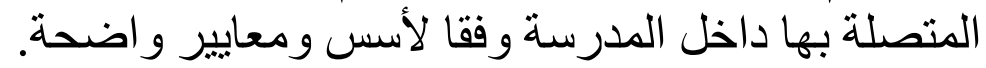
ـ ـ دعم المجتمع: يساهم المجتمع ومؤسساته في دعم استخدام التكنولوجيا وتقديم الخبرة اللازمة لتفعيله.

ـ سياسات المساندة: توجيه السياسات المدرسية والجامعية لاعم تفعيل التكنولوجيا في العملية التعليمية.

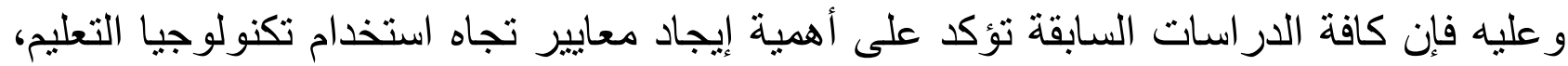
و أهمية تمكين المعلمين بالاستناد إلى كفايات محددة و إجر اء التقييم المستمر للاستخدام وفقا لأسس ومعايير و اضحة. منهج الدراسة: لقد تم إتباع المنهج الوصفي في هذه الدر اسة، انطلاقا من تحديد الأهداف التي انبثقته عن المشكلة.

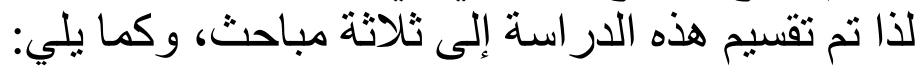
المبحث الأول: أهمية تكنولوجيا التعليم في عمليتي التعليم والتعلم

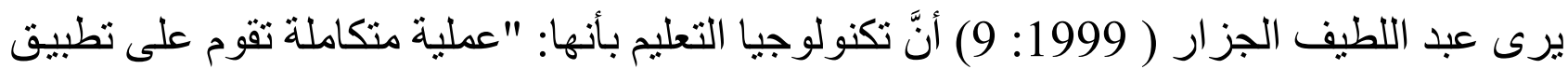

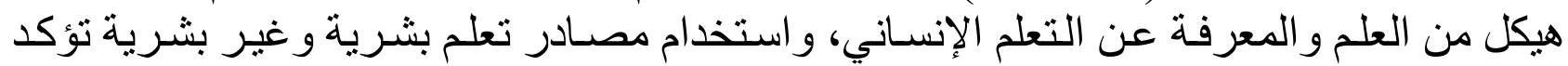


نشاط المتعلم وفرديته بمنهجية أسلوب المنظومـات، لتحقيق الأهداف التعليمية و التوصل إلى تعلم أكثر فعالية". ويمكن توضيح مفهوم تكنولوجيا التعليم وفقا لهذا التعريف في شكل رقم التهية (1):

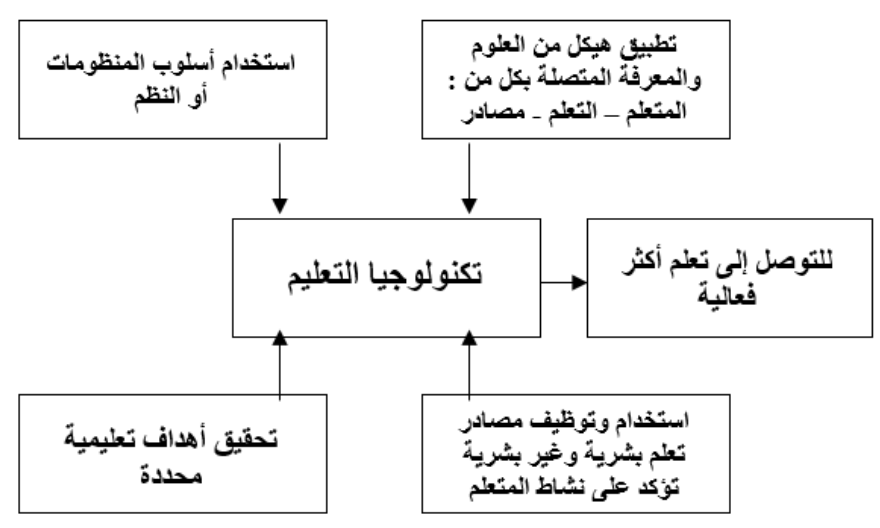

شكل (1) مخطط يوضح مفهوم تكنولوجيا التعليم

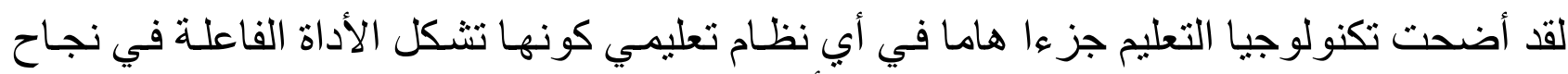

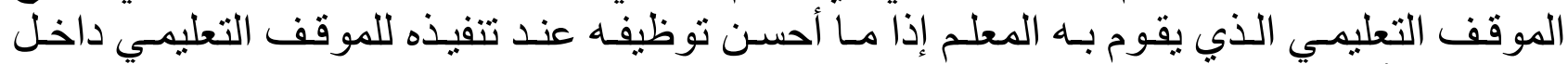

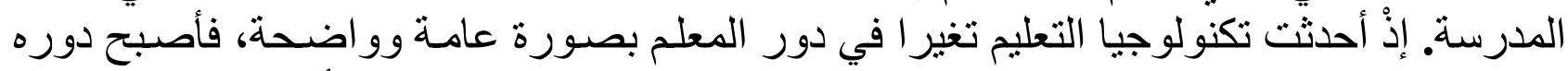

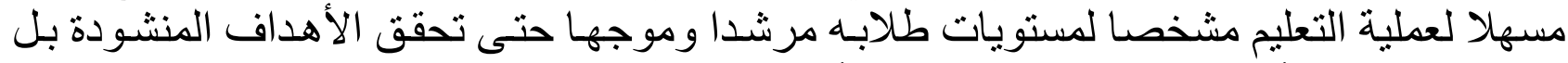

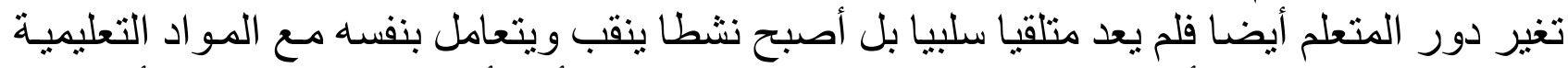

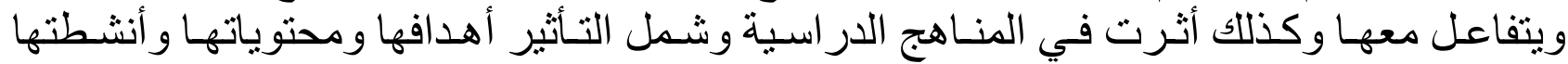
وطرق عرضها وتقديمها وأساليب تقويمها النيا (عبد المنعم، 1996: 277).

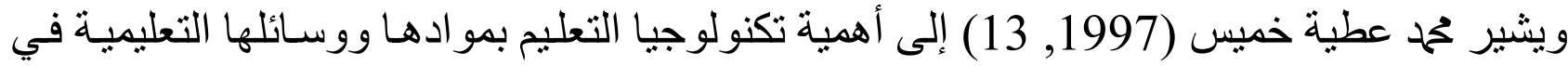

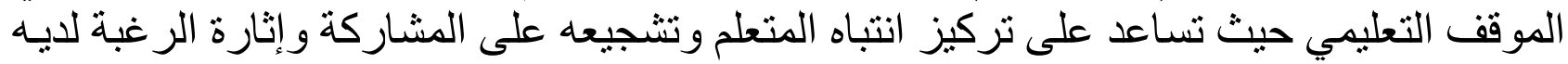

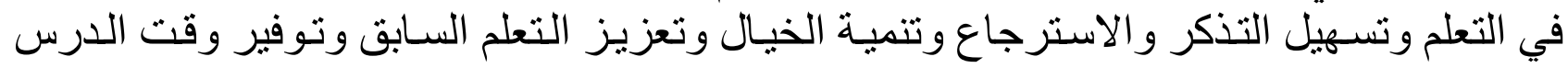

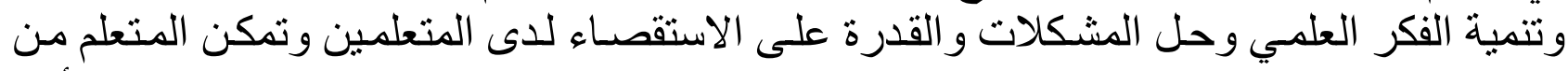

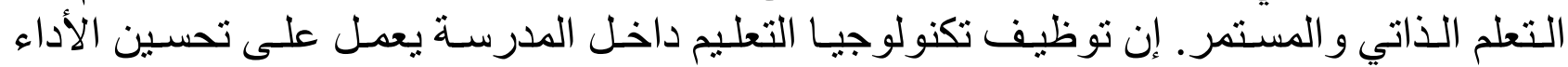

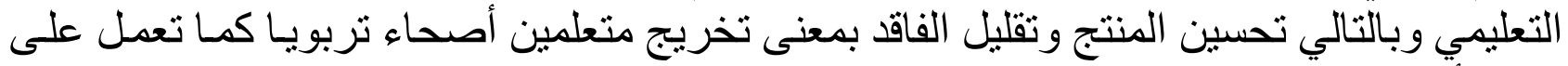

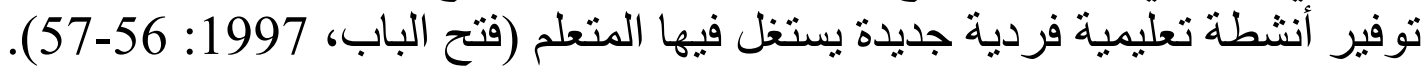
كما يمكن تحديد أهمية تكنولوجيا التعليم في العملية التعليمية و أهميتها بالنسبة للمعلمين و والطلبة فية

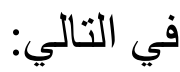

بالنسبة للعملية التعليمية: يرى كثير من المربين بصفة عامة و المتخصصين في مجال تكنولوجيا

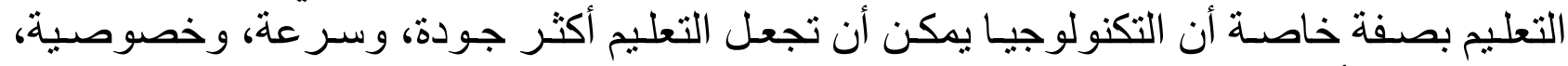

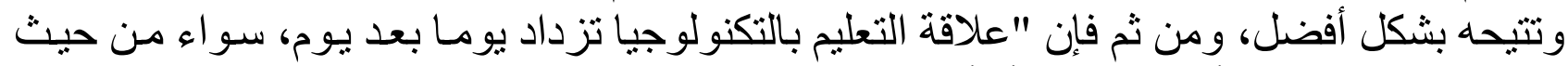

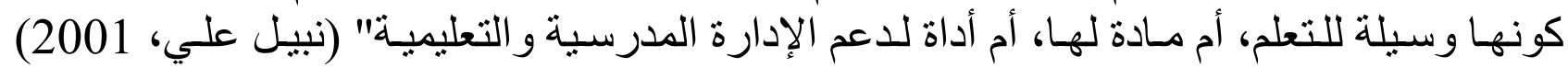

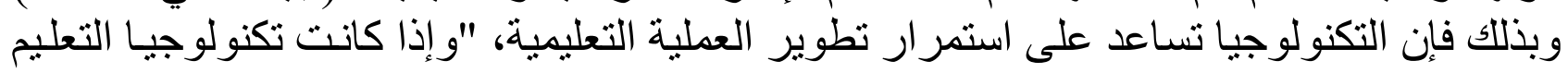

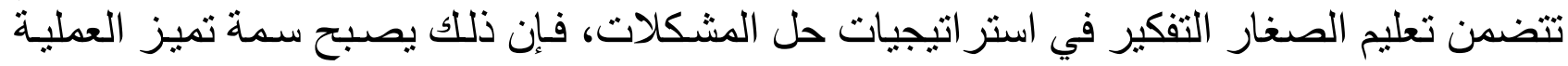
التعليمية في مختلف مر احلها". (Terry, 1996: 7). 


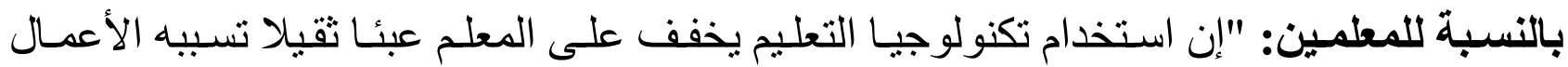

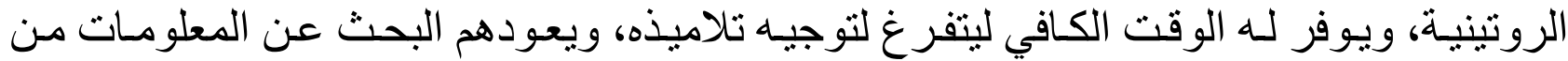

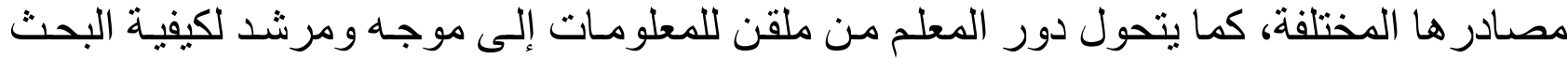

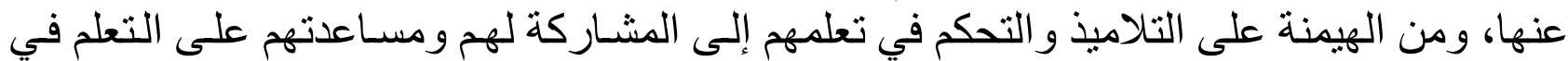

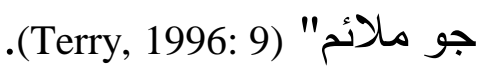

بالنسبة للتلاميذ: تساعد تكنولوجيا التعليم في تحقيق ما يلي: • تعليم الأعداد المتز ايدة من التلاميذ، و التعامل معهم بفاعلية، تبعدهم عن اللفظية و التلقين.

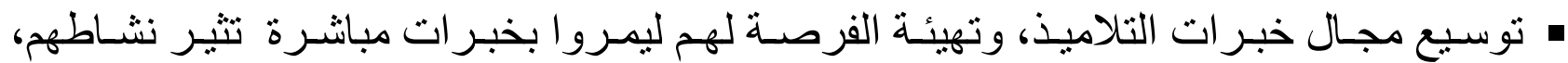
وتحفز هم على التفكير الابتكاري، مما يعودهم على التعلم الذاتي واستمر ار ممارستهم لله. معالجة الفروق الفردية بين التلاميذ، و العمل على تحقيق قدر كبير من تكافؤ الفرص التعليمية

بينهم، حيث تتاح لبطيئي التعلم عرض المادة التعليمية أكثر من مرة. (محمد هاثنم، 1991 192: 72).

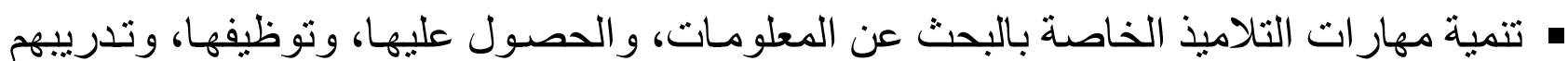

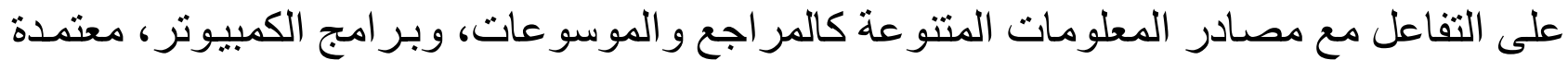

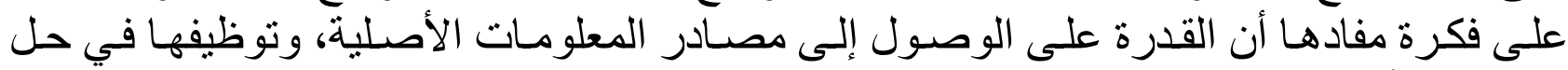

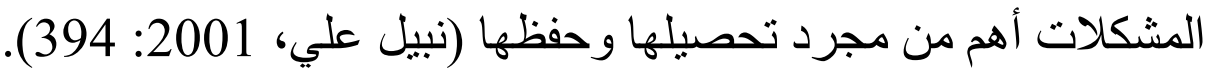
ويحدد مصطفى عبد السميع وآخرون (2005: 36-38) أهمية تكنولوجيا التعليم في عمليتي التعليم و التعلم في العديد من النقاط نذكر منها:

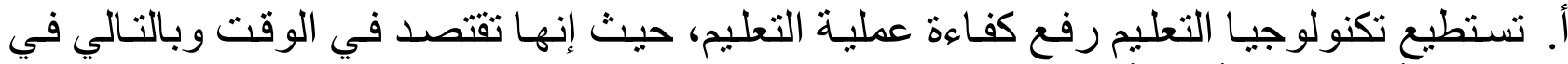
الجهد لمسألة الجهد الأثر الأكبر في الإسر اع في في عملية التعلم.

ب. تسهم تكنولوجيا التعليم في المنظومة التعليمية في إيجاد عنصر التعزيز التئر في عملية التعلم، ممـا

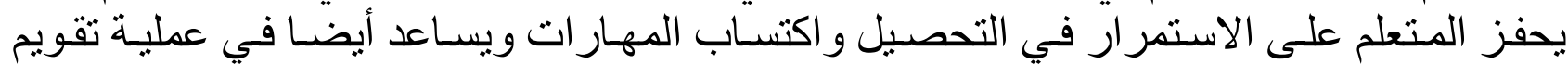

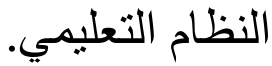

ت. توفر تكنولوجيا التعليم للعملية التعليميـة مزيدا من الكفاءة و الفعاليـة فالمعلم وحده مهمـا كانت إمكاناته الذاتية محدود الطاقة، و التكنولوجيا التعليمية تزيد من إمكاناته وطاقاتها

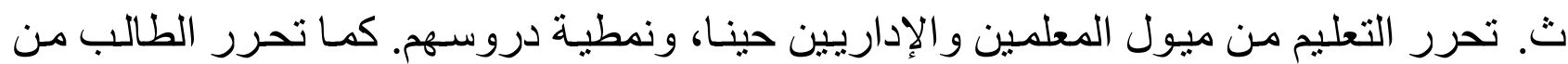

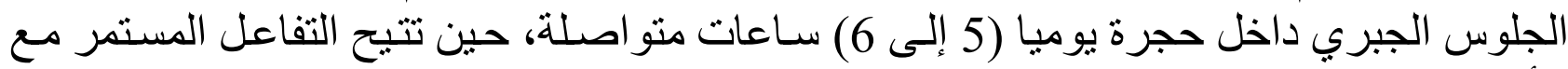
الأجهزة الإلكترونية الحديثة الموجودة بوديا بالمدرسة التي تسهم في تحسين عملية التعلم. ج.تجعل الاحتكالك بين المتعلم وبين ما يتعلمه احتكاكا مباشر ا فعالا.

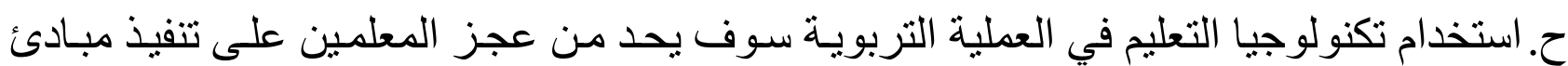

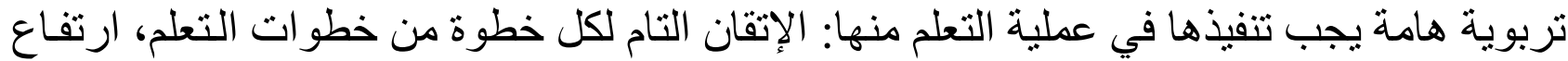

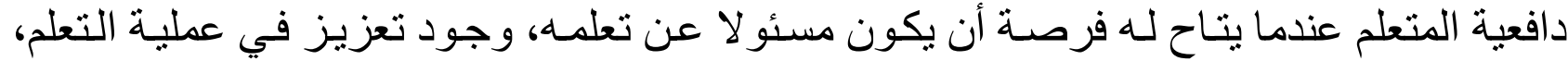
يتعلم كل طالب بمعدله نظر اللتفاوت الكبير في معدلات التعلم بين الطلبة. خ. إن أهمية تكنولوجيا التعليم كوسيط مرئي ومسموع يسـاعد على استثارة دافعية و اهتمـام الطلبة 
و إثباع حاجاتهم التعليمية، بالإضـافة إلى زيادة خبرات الدارس مما يجعله أكثر استعدادا للتعلم كمـا

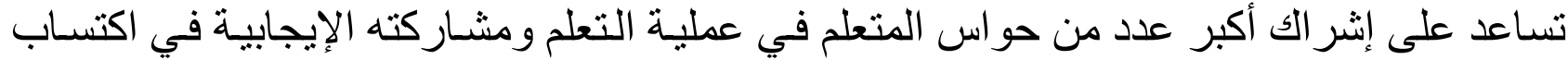
الخبرة وتنمية قدرته على الملاحظة و إتباع التفكير العلمي للوصول إلى حل المشكلاته، كمـا تسـاعد على مواجهة الفروق الفردية بين المتعلمين في ضوء تنوع استخدام حو اس المتعلم في التعلم وفقا لقدر ات الطلبة المختلفة.

\section{المبحث الثاني: تكنولوجيا التعليم والنموذج التربوي التكنولوجي المعاصر}

يتعدد دور تكنولوجيا التعليم في النظام التربوي الحديث المعزز بـالأدوات التكنولوجيـة المعاصـرة

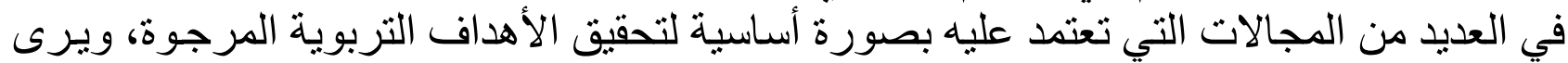

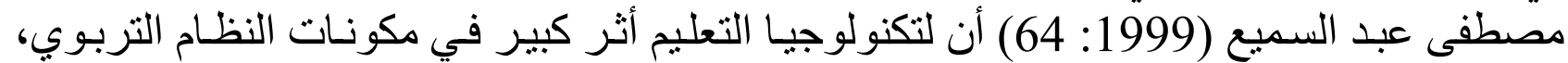

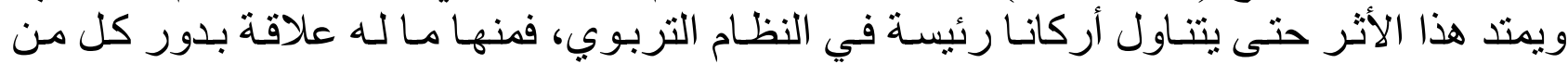

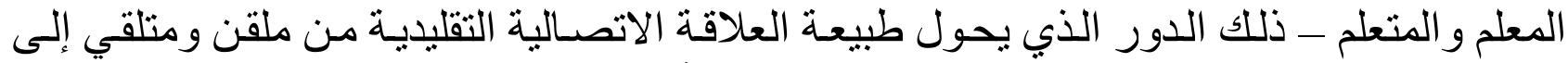

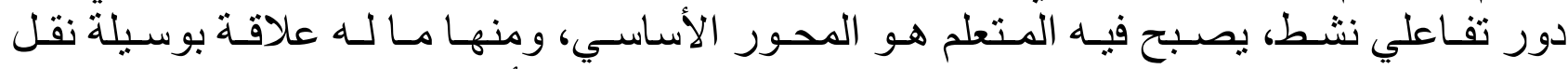
المعلومات. ففي النظام التربوي التقليدي كان المعلم هو المصدر الأساسي لنقل المعلومـات للتلميذ، وفي النظام التكنولوجي تتعدد وسائل نقل المعلومسات إلى عدد كبير من وسـئئل الاتصـال التربوي كالتلفزيون و الكمبيوتر و غير ها من مصنادر المعلومات

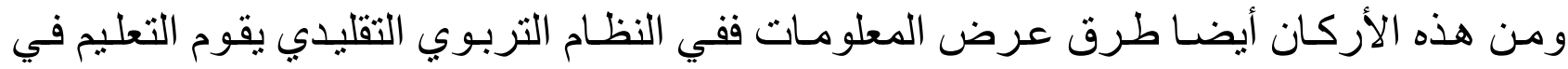

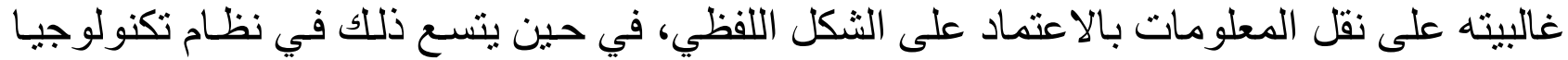

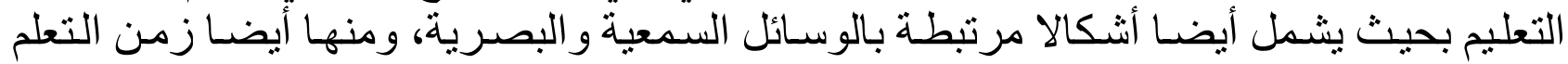

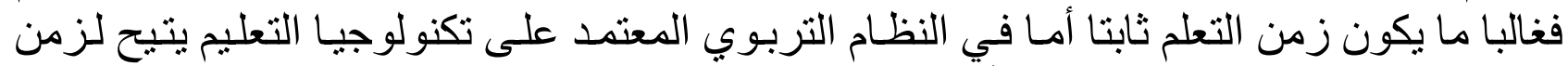

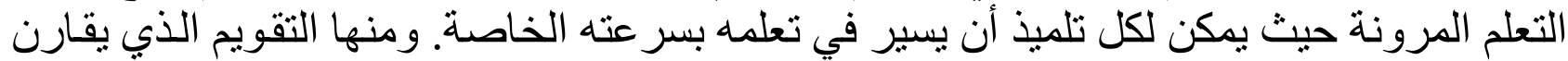

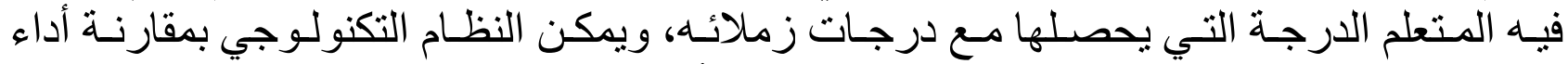
المتعلم وقياس مدى التقدم الذي حققه المتعلم في تحليل أهداف درج الدرس.

ويرى (1992: 31-37 إن إدخال تكنولوجيـا التعليم في التدريس عمليـة تغيير تربـوي منظم، تؤدي إلى تغير في بعض جوانب بيئة التعلم، وقد رسم بعض التربويين أبرز ملامسح هذا التغيير فكانت كالتالي:

أ. التحول من الصنف الكامل إلى المجمو عات الصغيرة . ب. التحول من العمل مع أفضل التناميذ إلى العمل مع كل التلاميذ. ت. التحول باتجاه إشغال التلاميذ أكثر. ث. التحول من التنافس إلى البناء الاجتماعي التعاوني. ج. التحول من أن كل المتعلمين بتعلمون نفس الثـيء إلى أن المتعلمين المختلفين يتعلمون أشياء مختلفة.

ح. التحول من التفكير إلى التفكير اللفظي البصري. و عليه مما سبق فإن أهمية تكنولوجيا التعليم في عمليتي التعليم و التعلم بتمثل في قدرتها على تجويد

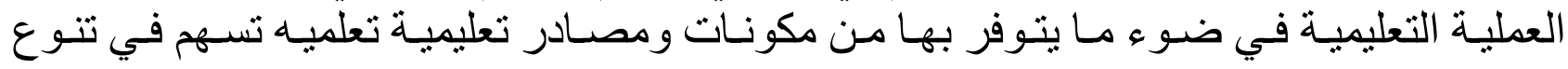




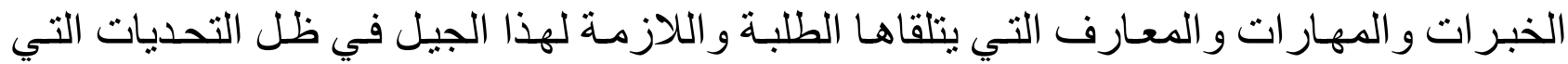

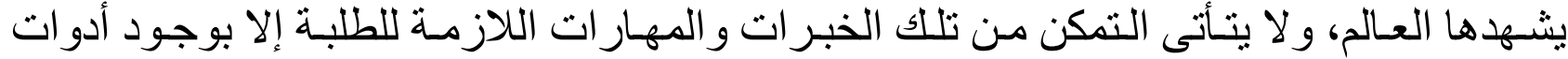

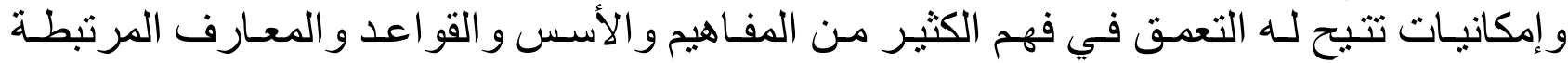

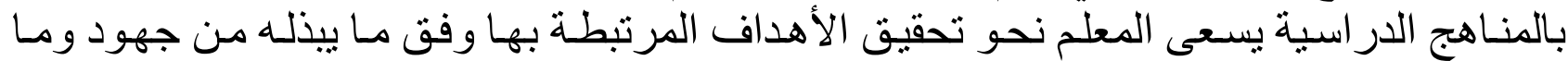
يمتلكه من كفايات لازمة لتفعبل استخدام تكنولوجيا التعليم في عمليتي التعليم و التعلم. مكونات مجال تكنولوجيا التعليم:

لقد كانت هنالك العديد من المحاو لات لتحديد مكونات مجال تكنولوجيا التعليم وذلك في ضوء تطور تلهور تكنولوجيا التعليم و العمليات المتعلقة به. وتثير باربـار اسيلز (1998: 69) إلى تصدورين في هذا الجانب هما:

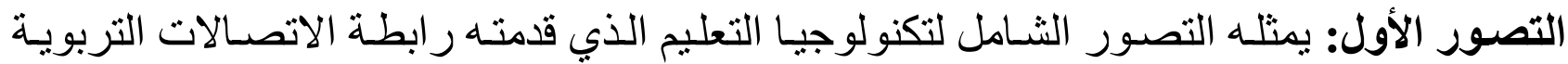
و التكنولوجية في الو لايات المتحدة الأمريكية (AECT) عام 1979 على أنها ثلاثتة أجز اءه ومنكاملـة لا يمكن فصلها و هي:

(أ) مجال تكنولوجيا التعليم: يتكون مجال تكنولوجيا التعليم من ثمانية مكونـات هي مكونـات التعليم

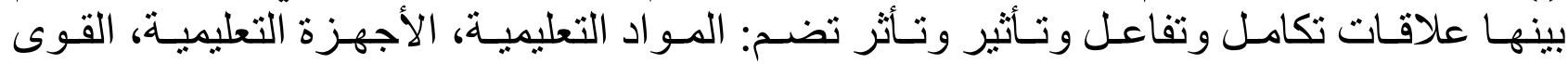

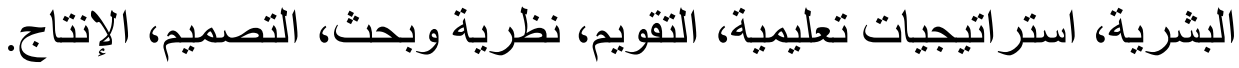
(ب) عمليـة تكنولوجيـا التعليم: تكنولوجيـا التعليم كعمليـة هـي مخطط منهجي للاستخدام المنظم

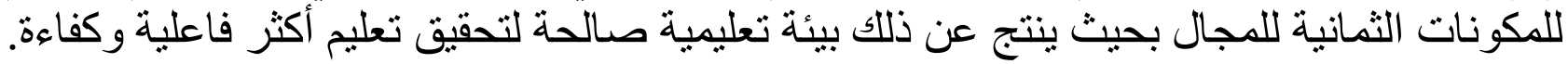
(ج) مهنة تكنولوجيا التعليم: من حيث اعتبار تكنولوجيا التعليم مجـال له مجمو عـة مكونات ولكل

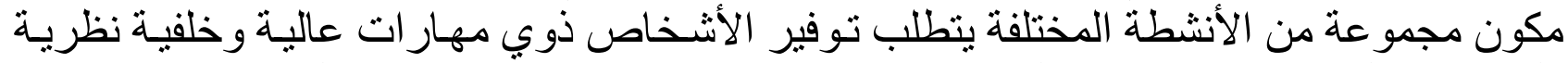
لأداء هذه الأنشطة ودن هؤلاء الأفر اد: المصسم التعليهي، المبرمج التعليمي، أخصسائي تكنولوجيـا

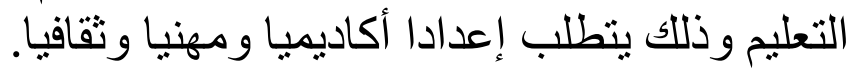

التصور الثاني: و الذي يمثل تعريف جمعية الاتصالات التربويـة و التكنولوجيـة الأمريكية (AECT)

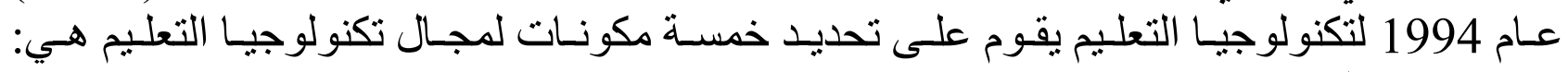
التصميم، التطوير، الاستخدام، الإدارة، التقويم. ويوضح الثكل (2) هذه المكونات: 


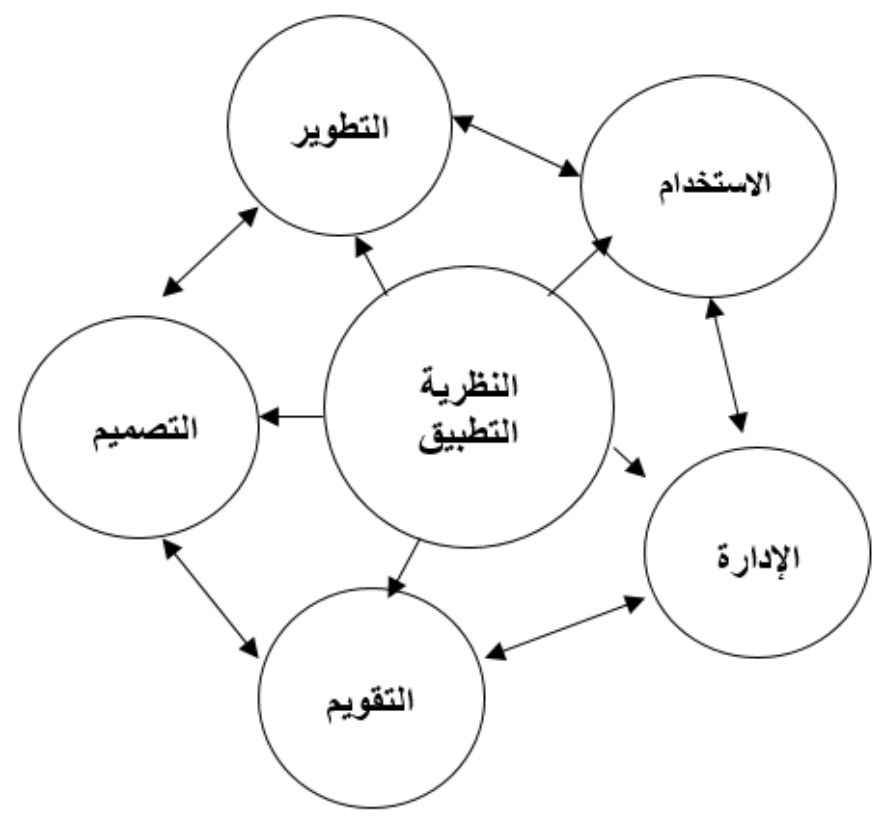

الثكل (2) مكونات تكنولوجيا التعليم

تشير باربـار ا سيلز (1998، 71) إلى كل مكون من مكونـات تكنولوجيا التعليم وفق الثكل(2) بالتالي:

أ. التصميم: ويهتم مجال التصميم بتصميم النظم التعليمية وتصميم المو اد و الاستر اتيجيات التعليمية

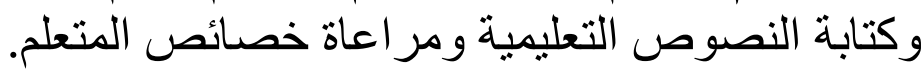

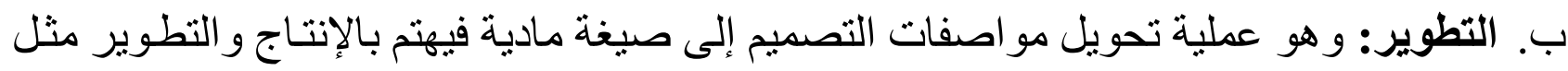

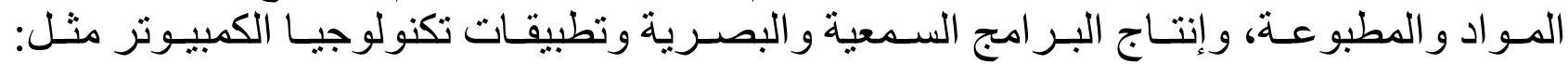

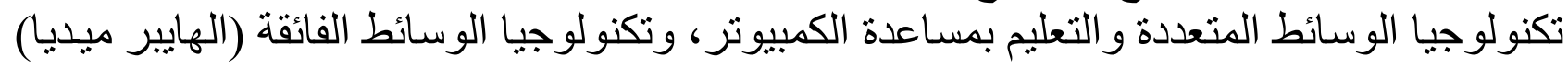

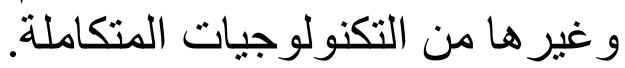

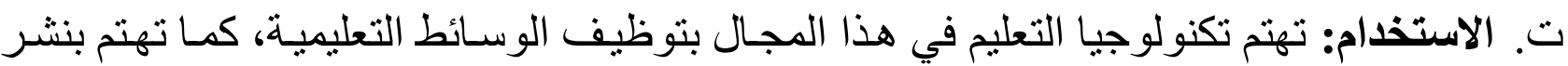

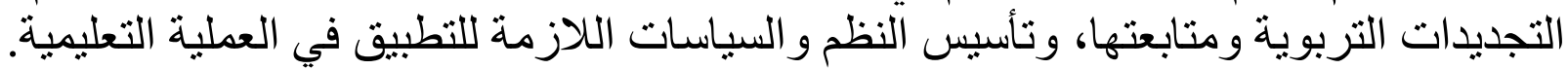

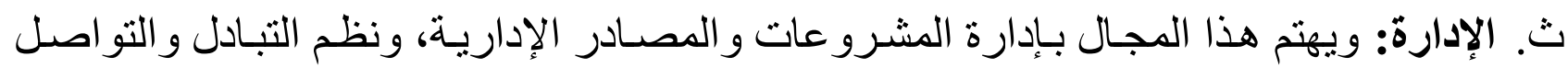

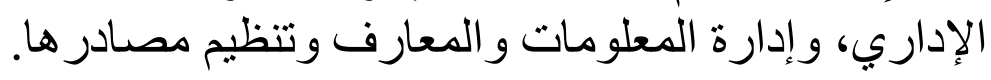

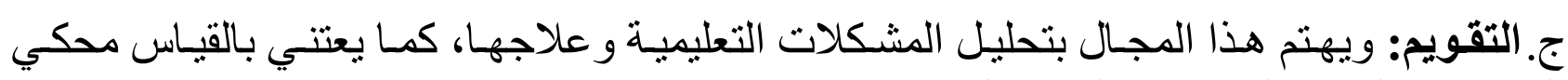
المرجع، و التقويم التكويني و التقويم النهائي.

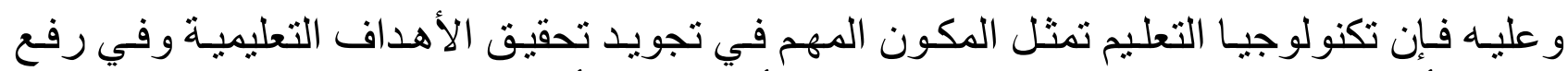

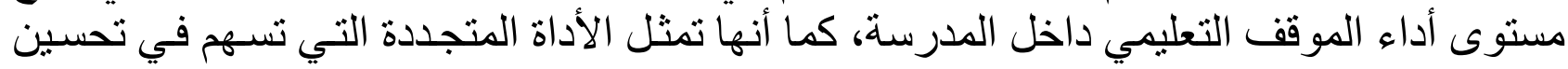

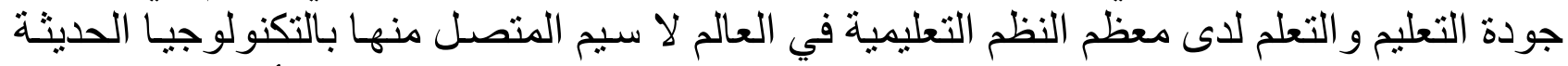

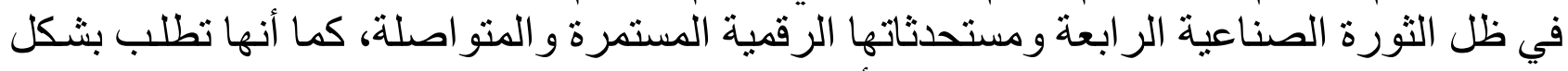

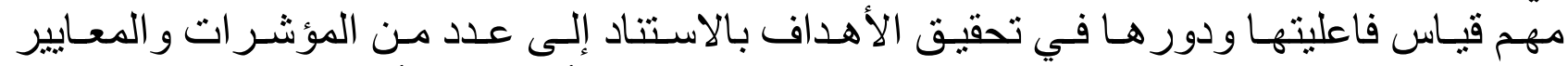

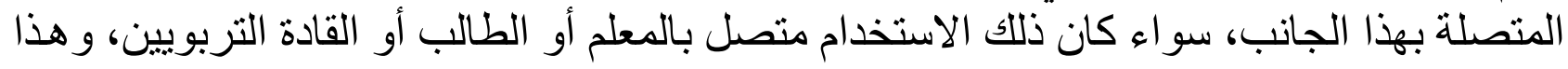


ما سنشير إليه في الجزء الثاني من هذا المقال. المبحث الثالث: المعايير الدولية لاستخدام تكنولوجيا التعليم في العملية التعليمية

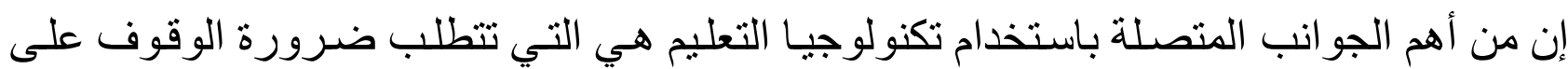

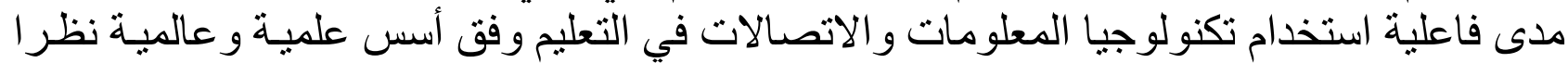

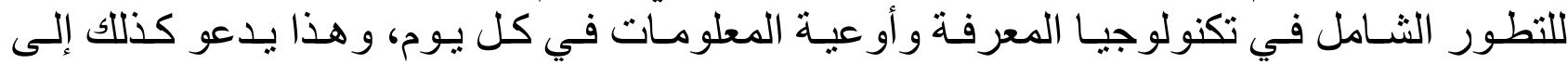

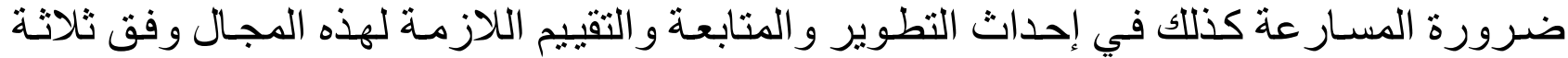

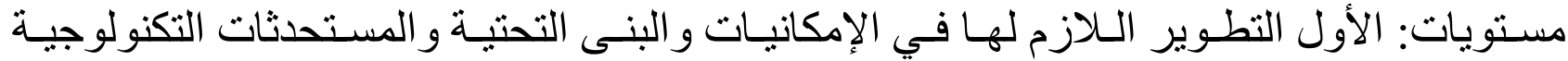

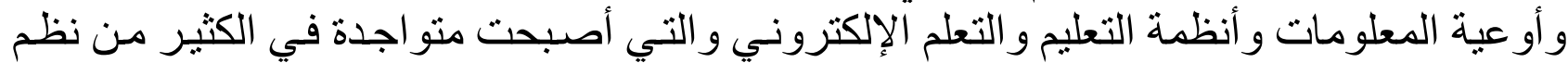

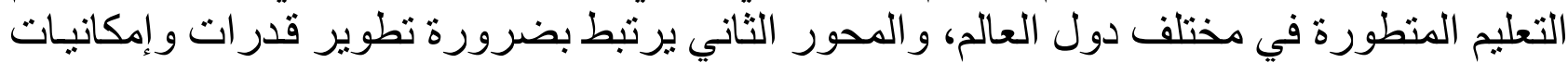

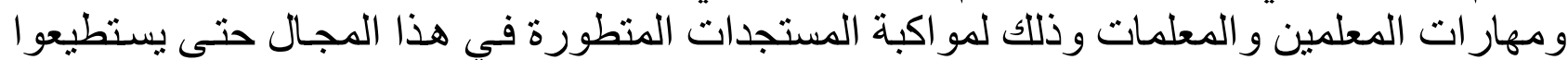

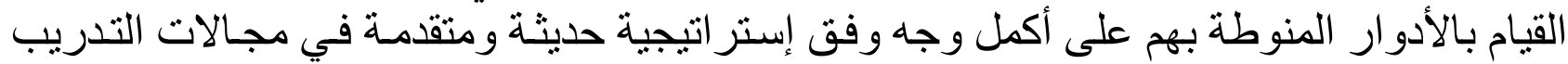
و التأهيل المتصلة في عمقها المهني بمعايير استخدام التكنولوجيا في فملي التيتي التعليم والتعلم.

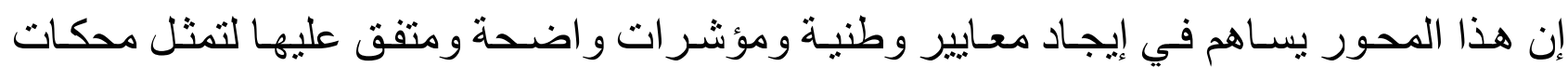

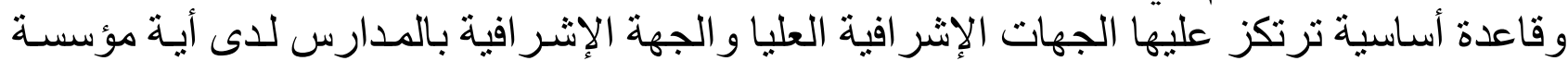

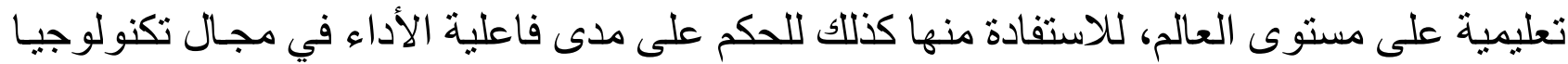

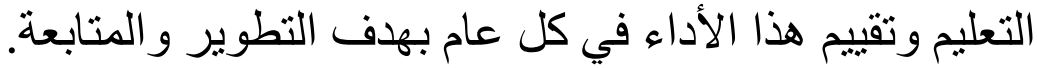

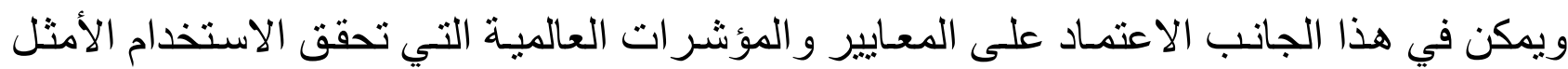

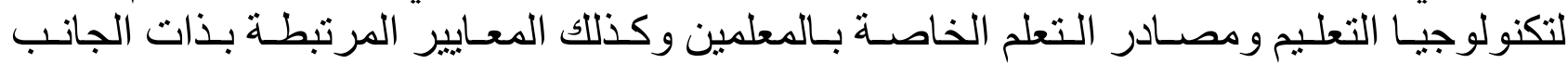
و الخاصة بالطلبة.

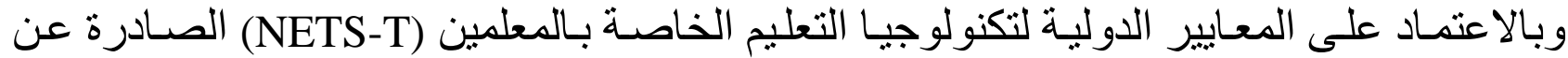

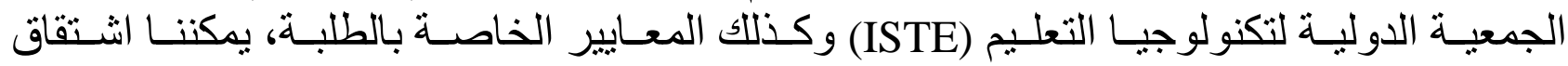

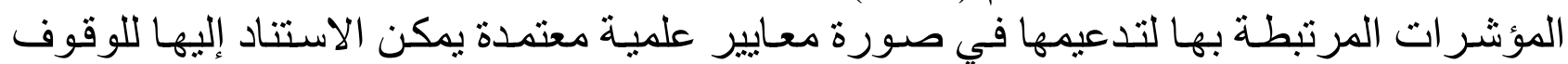

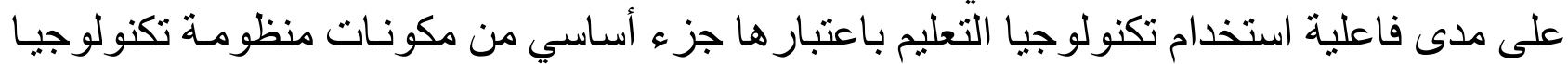
التعليم، وتشمل هذه المعايير ومؤشر اتها:

معسايير تكنولوجيـا التعليم الصـادرة عن الجمعيـة الدوليـة لتكنولوجيـا التعليم Educational Technology Standards 1- معايير ومؤشرات تكنولوجيا التعليم الخاصة بالمعلمين:

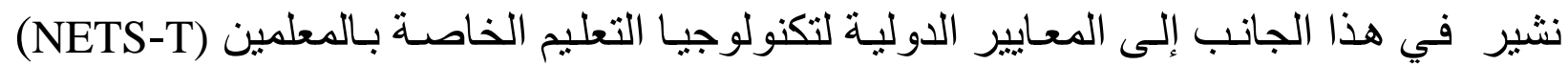

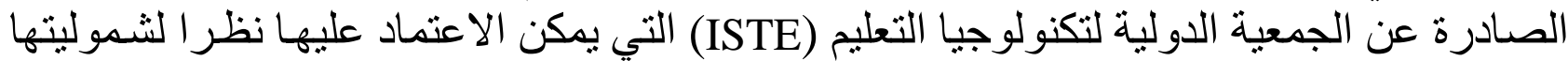

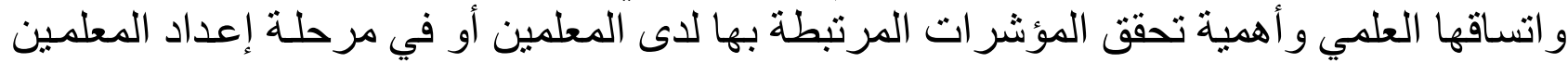

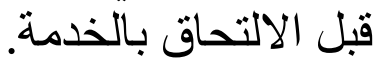

ولقد قدمت المعايير الدولية لتكنولوجيا التعليم الخاصـة بـالمعمين The ISTE National Educational) Technology Standards for Teachers)(NETS-T) مجموعـة مسن الإرشـادات (http://cnets.iste.org/teachers/pdf/sec_1-1_Establishing-NETST.pdf) لتطبيق التكنولوجيا في عملية التعليم والتي تحدد الجو انب التي يجب أن يتمتع بها المعلمين لتفعيل الإن 
Gary G. Bitter, Melissa E. Pierson (2007, . استخدام تكنولوجيا التعليم بصسورة فاعلـة بمدارسـهم

إن هذه المعايير مرتبة ضمن ست فئات و اسعة بثلاث و عثرين مهمة أدائية كما يأتي:

(أ) العمليـات والمفاهيم التكنولوجية Technology Operations and Concepts يظهر المعلمون فهمـا عميقا للعمليات والمفاهيم المرتبطة بتكنولوجيا التعليم حيث يقومونه بـ: • إظهار المعرفة و المهار ات الأولية واستيعاب المفاهيم ذات العلاقة بتكنولوجيا التعليم. • إظهار نمو مستمر في المعرفة التكنولوجية و المهارات للبقاء على اطلاع على التقنيات الحديثة. Planning and Designing Learning Environments and ب) تخطيط وتصميم بيئات وخبرات تعليمية يخطط ويصمم المعلمون بيئات تعليمية فعالة وخبرات قائمة على تكنولوجيا التعليم حيث يقومون ب:

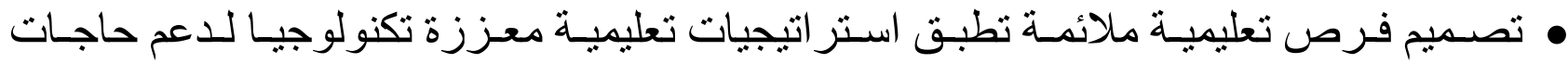
المتعلمين. القيام بأبحاث عن التعليم و التعلم بوساطة التكنولوجيا عند التخطبط للبيئات و الخبرات التعليمية. • تحديد وتعيين مصادر تكنولوجية و تقدير ها فيما يخص الدقة و الملائمة. • التخطبط لإدارة التكنولوجيا ضمن محتوى الأنشطة التعليمية. التخطيط لاستر اتيجيات لإدارة تعليم الطلبة في بيئة معززة تكنولوجيا.

(ج) التعليم، والتعلم، والمنهـاج Teaching, Learning and the Curriculum ينفذ المعلمون خطط المنهاج التي تتضمن أسـاليب واستراتيجيات تعليمية تعلميه قائمسة على تكنولوجيا التعليم حيث يقومون ب-:

• تسهيل الخبر ات المعززة تكنولوجيا التي تبين مقاييس كل من المحتوى وتكنولوجيا التعليم. • استخدام التكنولوجيا من اجل دعم الإستر اتيجيات التي تركز على المتعلمين والتي تبين حاجـات الطلبة. • تطبيق التكنولوجيا من اجل تطوير مهار ات عالية المستوى وإبداع لدى الطلبة. إدارة أنشطة التعلم الخاصة بالطلبة في بيئة معززة تكنولوجيا.

(د) التقيم والتقدير Assessment and Evaluation يستخدم المعلمون تكنولوجيـا التعليم من اجل تيسير مجموعة من استراتيجيات التقييم والتقدير الفعالة حيث يقومون بـ: • تطبيق التكنولوجيا في تقييم تعلم الطلبة لموضوع البحث باستخدام أساليب تقييم منتو عة. • استخدام مصادر التكنولوجيـة لجمع وتحليـل البيانـات وتفسير النتائج وربط المشـاهدات لتحسين

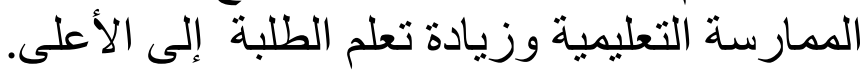
ه تطبيق أساليب متعددة من التقييم لتحديد مصادر التكنولوجيا الملائمة التي يعتمد عليها الطلبـة في 
تعلمهم وتو اصلهم و إبداعاتهز.

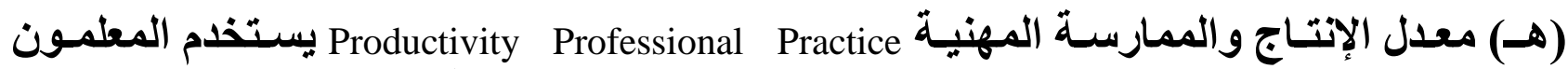
تكنولوجيا التعليم من اجل تحسين مخرجات التعلم وممارستهم المهنية حيث يقومون بـ: • استخدام مصادر التكنولوجيا للمشاركة في التطور المهني المستمر والتعلم الدائم.

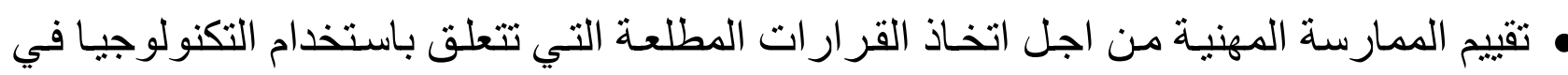
دعم تعلم الطلبة. م تطبيق التكنولوجيا من اجل زيادة معدل الإنتاج. • استخدام التكنولوجيـا في الاتصـال و التعـاون مـع الأقران و أولياء الأمور و المجتمع ككل لتغذيـة تعلم الطلبة.

\section{(و) القضايا الاجتماعية والأخلاقية والقانونية والإنسانية}

و يتفهم المعلمون القضـايا الاجتماعية والأخلاقية

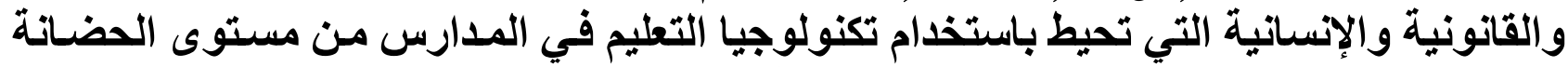

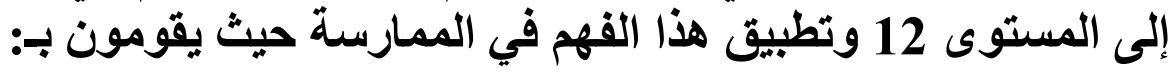

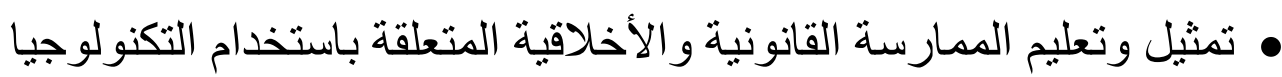

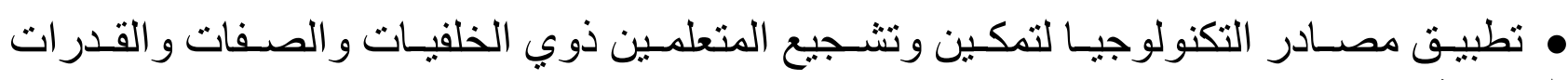
المتنو عة.

• تحديد واستخدام مصادر التكنولوجيا لتأكيد التنوع.

• ت تعزيز الاستخدام الآمن و الصحي لمصادر التكنولوجيا.

• تسهيل الوصول العادل لمصادر التكنولوجيا لجميع الطلبة.

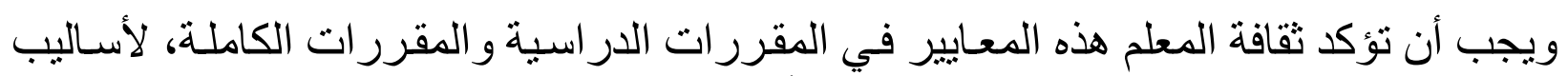

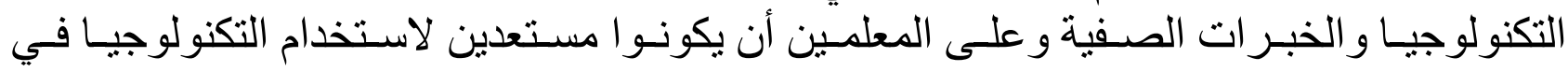

تعليمهر.

\section{2- معايير ومؤشرات تكنولوجيا التعليم الخاصة بالتلاميذ:}

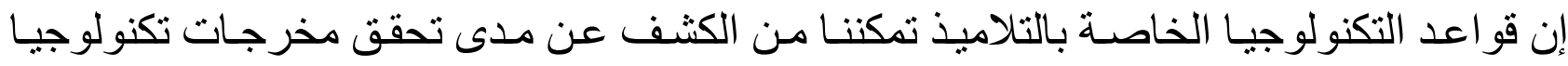

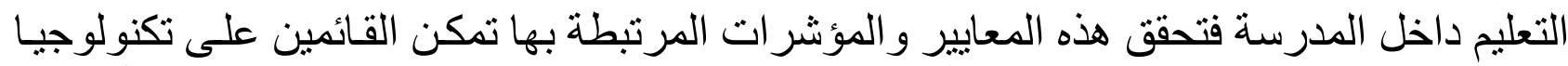

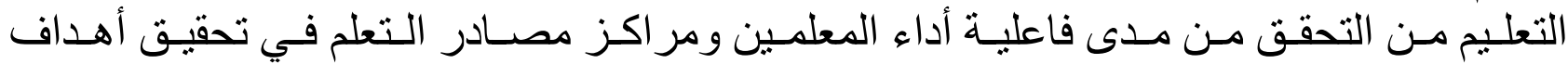

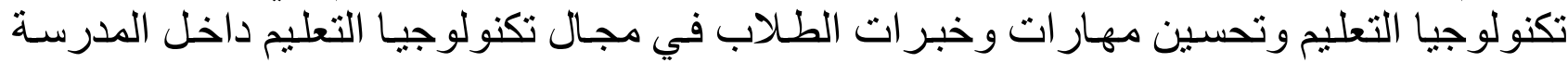

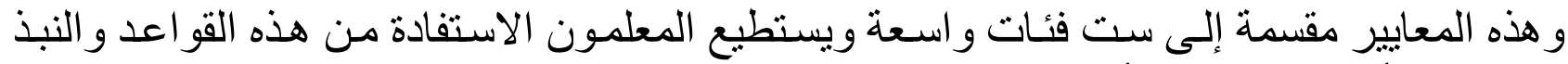

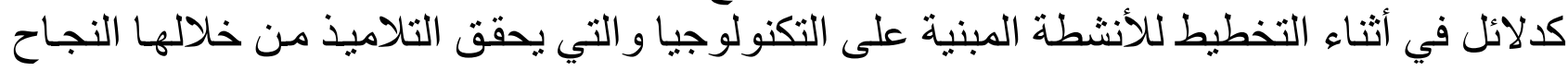

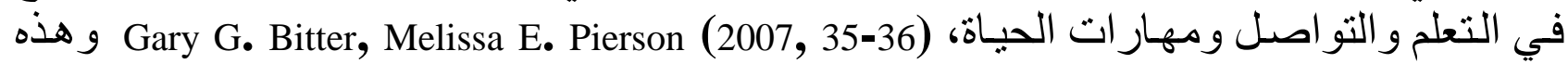
المعايير هي: فلم (أ) المفاهيم والعمليات الأساسية: 
• يظهر التلاميذ فهما عميقا لطبيعة وعمل الأنظمة التكنولوجية التي تساعدهم على التعلم. • التلاميذ بار عون في استخدام التكنولوجيا في مجال تعلمهم. (ب) القضايا الاجتماعية والأخلاقية والإنساتية:

• يستو عب التلاميذ القضايا الأخلاقية و التقافية والاجتماعية المتعلقة بالتكنولوجيا.

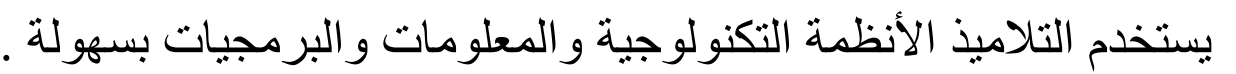

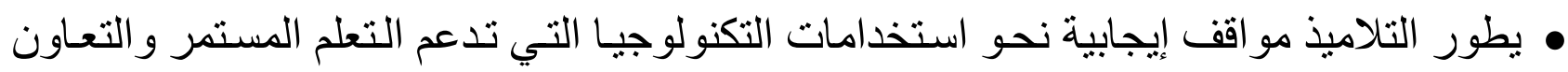
و المساعي الشخصية و الإنتاجية. (ج) أدوات الإنتاجية التكنولوجية: • يستخدم التلاميذ أدو ات التكنولوجيا لتحسين التعلم وزيادة معدل الإنتاجية ورفع الكفاءة.

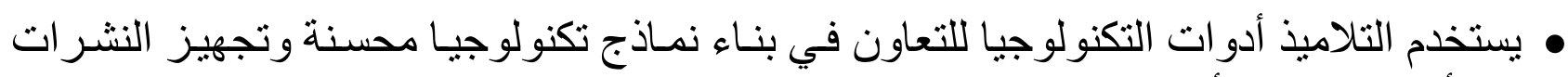

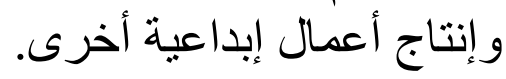
(د) أدوات الاتصالات التكنولوجية:

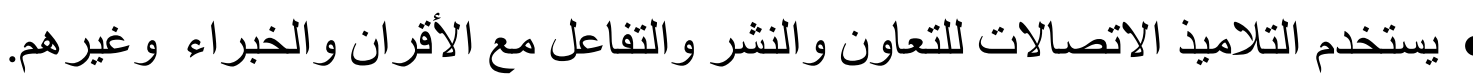

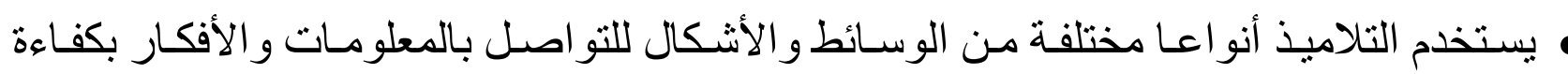

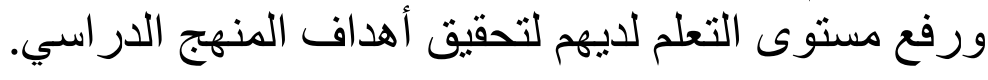
(هـ) أدوات البحث التكنولوجية: • يستخدم التلاميذ التكنولوجيـا لإيجـاد وتقيهم وجمـع المعلومـات مـن مصـادر مختلفـة في مجـال در استهم. • يشـارك التلاميذ المعلمين في استخدام الأدوات التكنولوجيـة لمعالجـة البيانـات ووضــع النتـائج التربوية.

• يقيم التلاميذ ويختارون مصادر معلومات جديدة وابتكار ات مبنية على ملاعمتها لمهام محددة. (و) أدوات تكنولوجية لحل مشكلات واتخاذ القرارات:

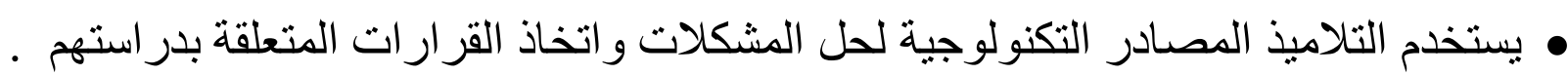

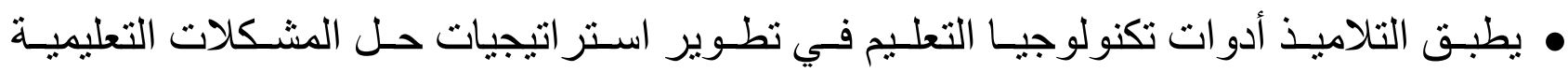

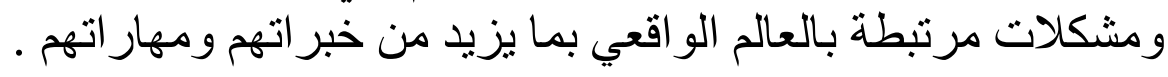
3- معايير ومؤشرات تكنولوجيا التعليم الخاصة بالمديرين (قادة التعليم):

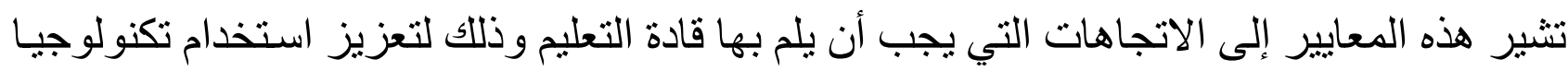

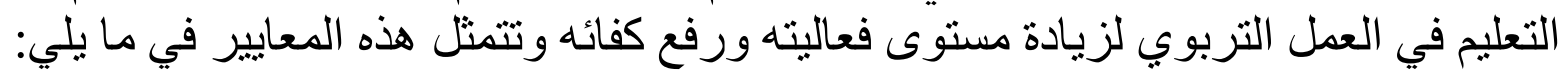

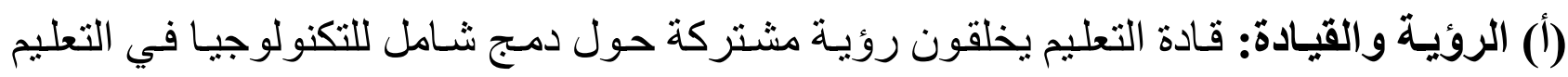

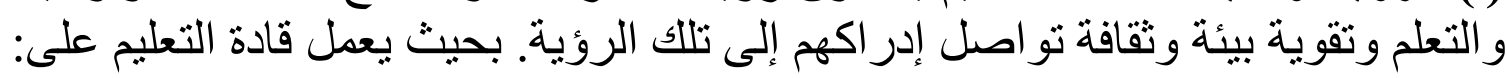


تسهيل التطوير المشترك من قبل جميع المساهمين نحو رؤية محددة لاستخدام التكنولوجيا داخل

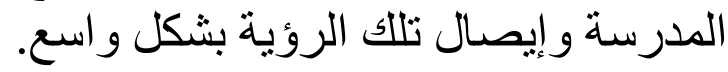

ه المحافظة على عملية شاملة لتطوير وتطبيق ومر اقبـة خطة تكنولوجية ديناميكية منظمـة لتحقيق

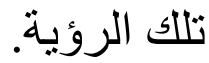

ز زرع وتقويـة ثقافة تحمل مسؤولية المخـاطرة وتبنـي سياسـات تعزز الابتكـار المستمر بوسـاطة

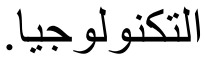

$$
\text { • ماستخدام البيانات في صنع القرارات القيادية. }
$$

ه تأييد الممارسات المبنية على الأبحاث في استخدام التكنولوجيا في التعليه. • تأييد السياسـات و البر امج على المستوبين المحلي و الوطني و إيجاد الفرص التي تدعم تطبيق الخطة المحلية لتكنولوجيا التعليم.

(ب) التعلم والتعليم: يؤكد قادة التعليم أن تصميم المنـاهج و استر اتيجيات التعليم و البيئات التعليمية المعززة بالتكنولوجيا الملائمة تحقق الحد التعلم الأعلى من التعلم و التعليم.

\section{حيث يعمل قادة التعليم على:}

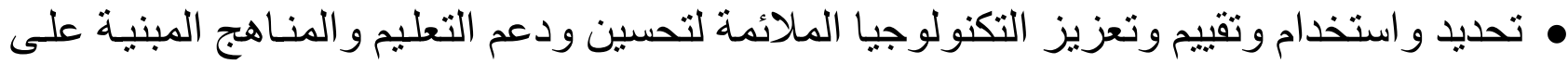
القو اعد التي تقود إلى مستوى عال من إنجاز ات الطلبة. • تسهيل ودعم البيئات التعليميـة التعاونية والغنية بالتكنولوجيا و التي تفضـي إلى الابتكار للتعليم

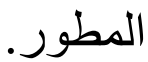

• تـوفير البيئـات المخصصـة للمتعلم التي تسـتخدم التكنولوجيـا لتحقيق حاجـات المتعلم الفرديـة

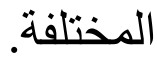

• تسـهيل و استخدام التكنولوجيـا لـدعم وتحسبن الأسـاليب التعليميـة التي تطور مهـار ات التفكير العالي وصنع القرار وات وحل المشكلات.

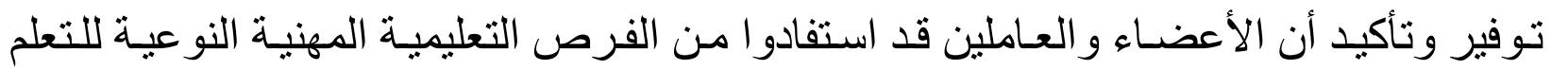

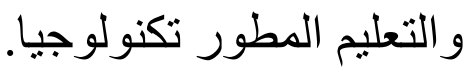

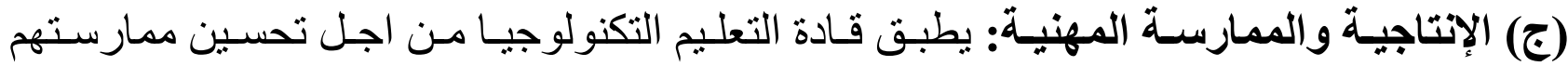
المهنية وزيادة معدل إنتاجيتهم ومعدل إنتاجية الآخرين.

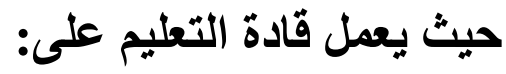

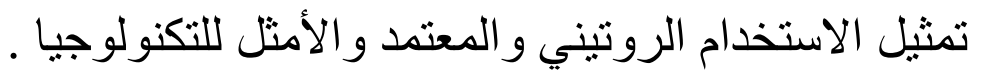

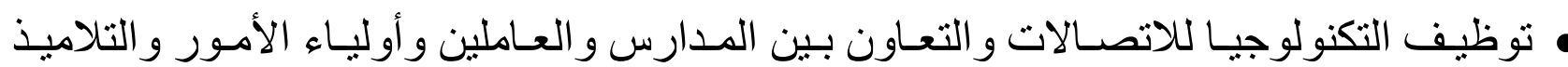

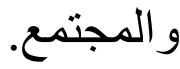

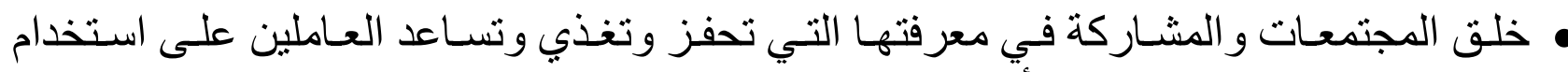
التكنولوجيا من اجل معدل إنتاجية أفضل. 
• المشاركة في تعليم مهني مثبت يتعلق بالعمل باستخدام مصادر التكنولوجيا. • الإبقاء على مو اكبة التكنولوجيا الحديثة واستخداماتها الممكنة في التعليم. • استخدام التكنولوجيا من اجل دفع الطور المؤسسي إلى الأمام. (د) الدعم, والإدارة, والعمليات: يضمن قادة التعليم دمج التكنولوجيا من اجل دعم الأنظمـة المنتجـة

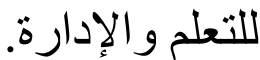

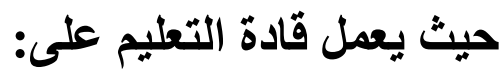
• تطوير وتطبيق ومر اقبة السياسات و الإرشادات لضمان تو افق التكنولوجيا. • تطبيق و استخدام النظم الإدارية و العملياتية المبنية على التكنولوجيا. إيجاد مصادر تمويل وقوى بشرية لضمان تطبيق كامل وقوي للخطـة التكنولوجية في المجـال التربوي.

دمـج الخطط الإستر اتيجية و التكنولوجيـة و الخطط التتمويـة ولسياسـات لتنسيق الجهود وفعالية المصادر.

• تطبيق إجر اءات لتوجيه التطورات المستمرة للأنظمة التكنولوجية التي تدعم العمل التربوي.

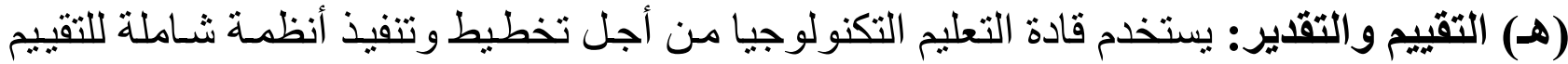

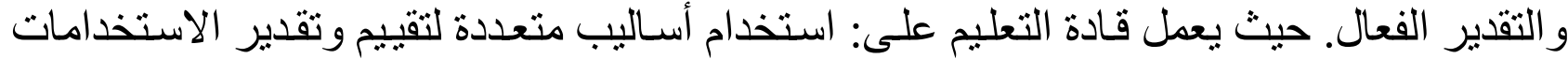
الملائمة لمصادر التكنولوجيا في التعليم والاتصالات و الإنتاجية. استخدام التكنولوجيا لتونيا لجمع وتحليل

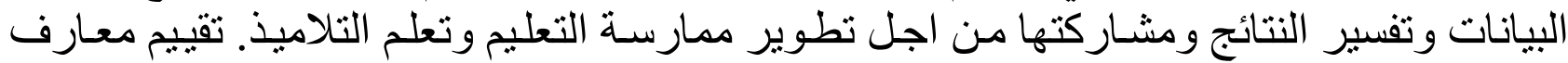

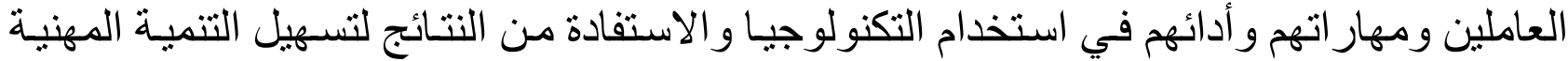

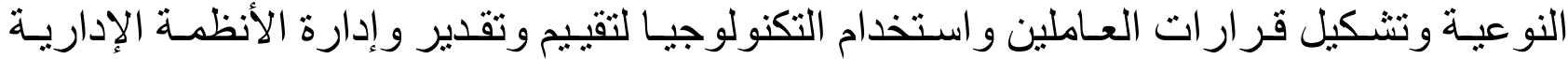
و والعملياتية.

(و) القضـايا الاجتماعيـة والقانونية والأخلاقيـة: يتفهم قادة التعليم القضـايا الاجتماعيـة و القانونية

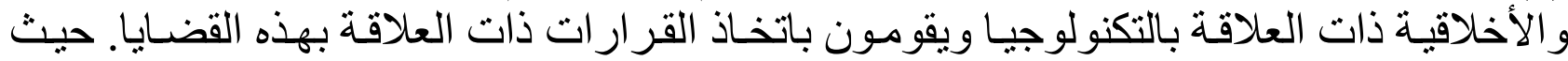
بعمل قادة التعليم على: الت العلى ـ ضمان العدالة في الوصول إلى مصادر التكنولوجيا وتقوية جميع المعلمين و المتعلمين. ـ تقوية السلوكيات الاجتماعية والقانونية و الأخلاقية لتحفيز الاستخدام المسؤول للتكنولوجيا. ـ تحفيز وفرض الخصوصية و الأمن و الأمان المتعلق باستخدام التكنولوجيا بالمدرسة. ـ تحفيز وفرض الممارسات الصحية والآمنة بيئيا في استخدام التكنولوجيا داخل المدرسة. ـ التأكيد على وضوح قانون حقوق الطبع وتحديد الملكية الفكرية. تطبيق المعايير الدولية لقياس فاعلية استخدام تكنولوجيا التعليم:

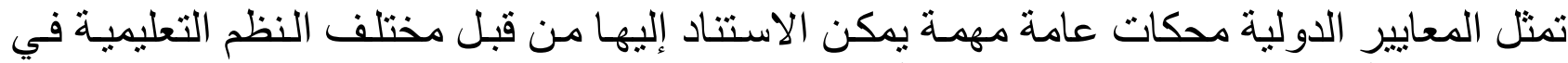
دول العالم، أو من قبل الباحثين التربويين أو من قبل الدر اسات والمر الثر اكز البحثية والتي من المككن 


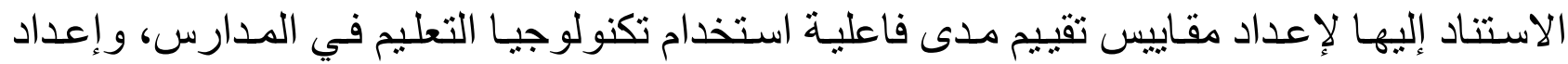

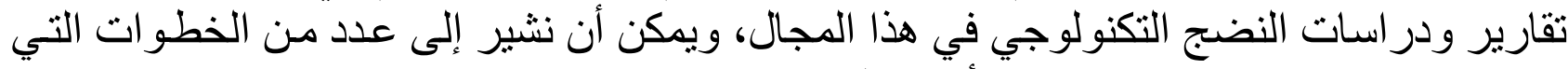
يمكن تنفيذها لتمكين هذه المعايير في أبي منظومة فئ تعليمية وفقا للتالي:

- إعداد قائمة المعايير النهائية.

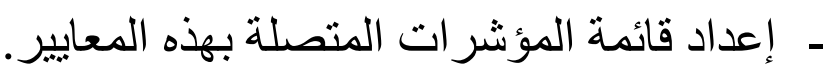
- - إعداد قائمة الكفايات التربوية المتصلة بالمؤشر ات و المعايير.

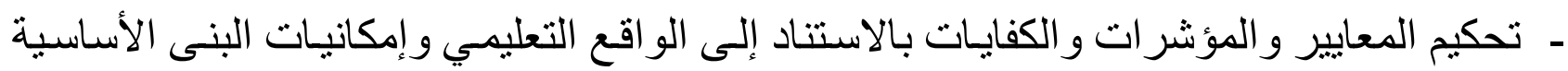
المتصلة بتكنولوجيا التعليم في المدارس. - - إعداد حقائب التدريب المتلائمة مع المعايير و المؤشر ات و الكفايات.

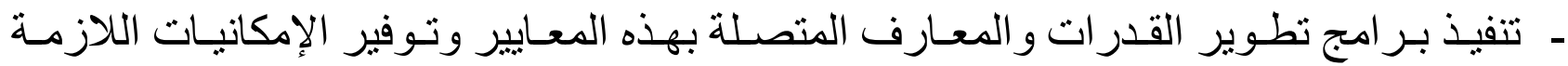
للتطبيق. - إعداد أدوات التقييم المتصلة بالمعايير وتشكيل فرق التقييم الخاصة بذلك.

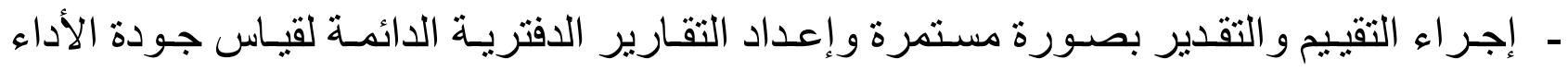
و تقديم التغذية الر اجعة و الخطط الداعمة لذلك.

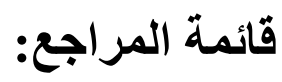

باربار ا سيلز ، ريتا ريتشي. (1998). التعريف ومكونات المجال. تكنولوجيا التعليم. ترجمة بدر الصـالح: مكتبة

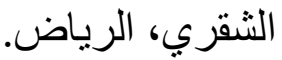

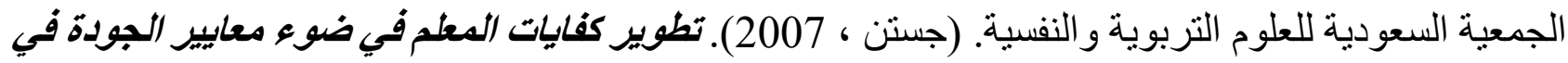
التعليم: القصيم، 15 مايو 2007م السعردية اللزيونة

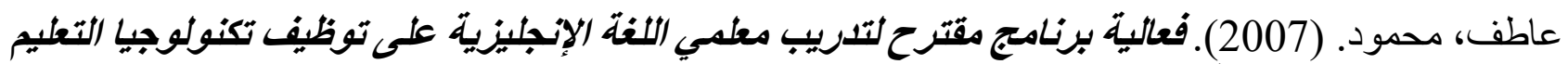

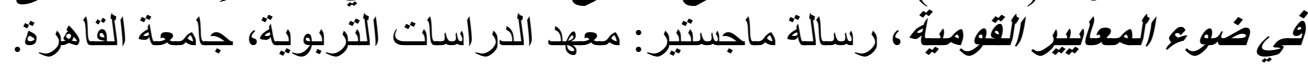
عبد اللطيف الجزار. (1999). مقدمة في تكنولوجيا التعليم النظرية والعدلية ، القاهرة.

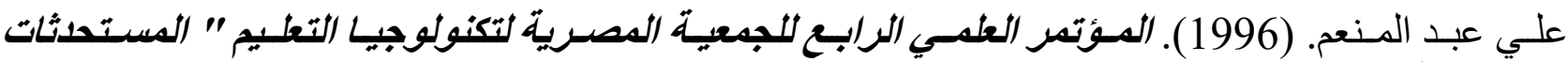

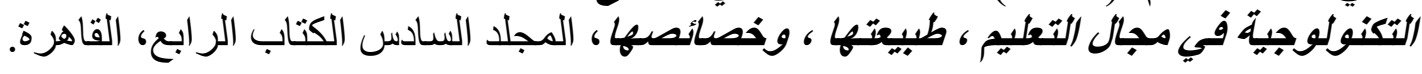

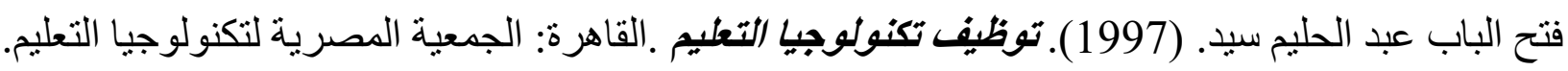

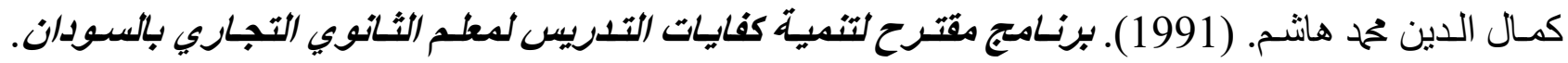
رسالة دكتور اه غير منشورة ،كلية التربية: جامعة عين شمس.

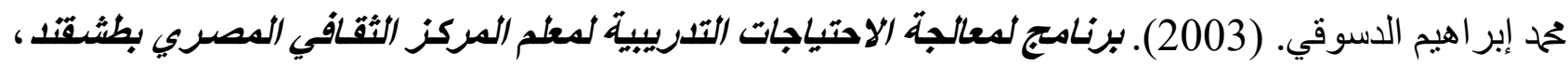
مجلة الجمعية المصرية لتكنولوجيا التعليم.

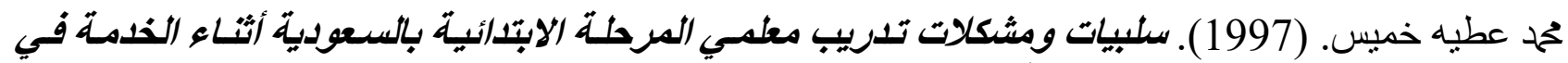

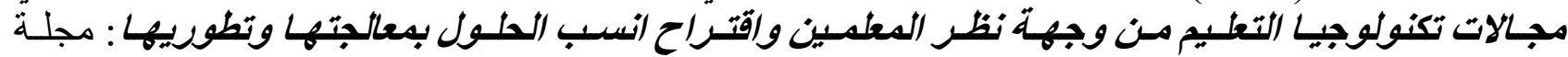
تكنولوجيا التعليم، المجلد السابع، الكتاب الأول. المشيقح، عبد الرحمن صالح. (1997). مشكلات توظيف تقنيات التعليم وسبل التغلب عليها ـ تكنولوجيا التعليم،

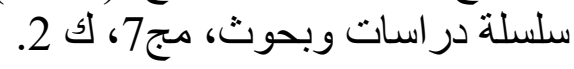




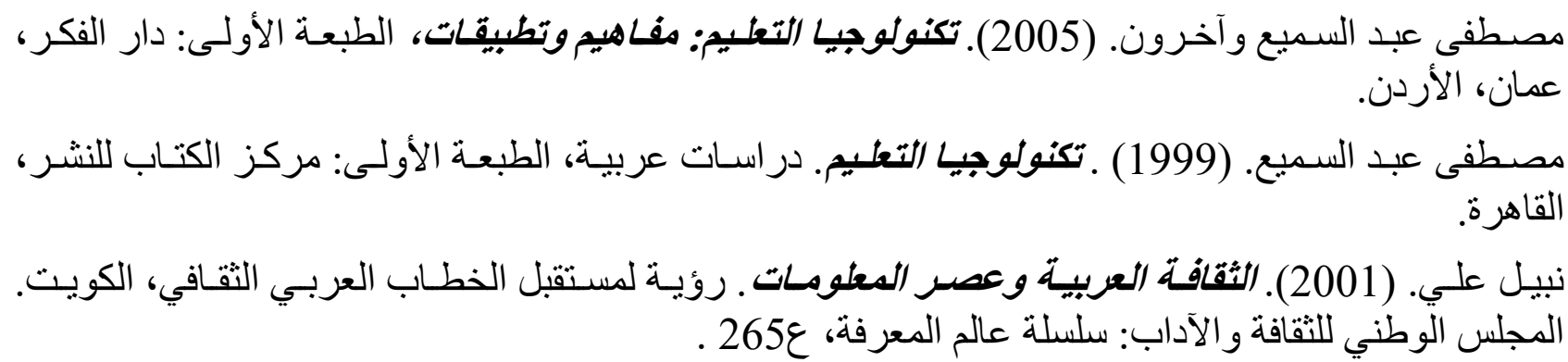

\section{ARABIC REFERENCES IN ROMAN ALPHABET}

Barbara Siliz, Rita Ritshi. (1998). Altaerif Wamukawanat Almajali. Tiknulujiaa Altaelim. Tarjamat Badr Alsalh: Maktabat Alshaqrii, Alriyad.

Aljameiat Alsewdyt Lileulum Altarbawiat Walnafsiat. (Jsatn , 2007). Tatwir Kifayat Almuelam fi Daw' Maeayir Aljawdat Fi Altaelim: Alqasim, 15 Mayu 2007m, Sa12-16.

Eatif, Mahmawd. (2007). Faealiat Barnamaj Muqtarah Litadrib Muelimii Allughat Al'iinjliziat Ealaa Tawzif Tiknulujia Altaelim fi Daw' Almaeayir Alqawmiati, Risalat Majstyr: Maehad Aldirasat Altarbawiati, Jamieat Alqahirat.

Eabd Allatif Aljazar. (1999). Muqadimat fi Tiknulujia Altaelim Alnazariat Waleamaliat, Alqahirat.

Eali Eabd Almaneum. (1996). Almutamar Aleilmiu Alrrabie Liljameiat Almisriat Lituknulujia Altaelim " Almustahdathat Altiknulujiat fi Majal Altaelim , Tabieatiha, Wakhasayisuha, Almujalid Alssadis Alkitab Alraabieu, Alqahirat.

Futih Albab Eabd Alhalim Sayd. (1997). Tawzif Tuknulujya Altaelim .Alqahirt: Aljameiat Almisriat Lituknulwjya Altaelim.

Kamal Aldiyn Muhamad Hashum. (1991). Barnamaj Muqtarah Litanmiat Kifayat Altadris Limaelam Althaanawii Altijarii Bialsuwdan. Risalat Dukturah Ghyr Manshurat ,Kaliat Altarbiati: Jamieat Eayan Shums.

Muhamad 'librahim Aldsuqi. (2003). Barnamaj Limuealajat Alaihtiajat Altadribiat Limuelim Almarkaz Althaqafii Almisrii Bitashqnid, Majalat Aljameiat Almisriat Lituknulwjia Altaelim.

Muhamad Eatih Khumis. (1997). Salbiaat Wamushkilat Tadrib Muelimiu Almarhalat Alaibtidayiyat Bialsaeudiat 'Athna' Alkhidmat fi Majalat Tiknulujia Altaelim Min Wijhat Nazar Almuealimin Waiqtirah Ainsib Alhulul Bimuealajatiha Watatawrayiha: Majalat Tuknulujiaa Altaelimi, Almujalid Alsaabiei, Alkitab Al'awl.

Almushiqih, Eabd Alrahmin Salh. (1997). Mushkilat Tawzif Taqniat Altaelim Wasubul Altaghalub Ealayha. Tiknulujia Altaelimi, Silsilat Dirasat Wabihawthin, Majan7, K2.

Mustafaa Eabd Alsamie Wakharun. (2005). Tiknulujiaa Altaelim: Mafahim Watatbiqat, Altibeat Al'uwlaa: Dar Alfukru, Eumaan, Al'urdunn.

Mustafaa Eabd Alsamie. (1999) . Tiknulujya Altaelima. Dirasat Earabiata, Altibeat Al'uwlaa: Markaz Alkitab Lilnushri, Alqahirat.

Nabil ali. (2001). Althaqafat Alearabiat Waeasr Almaelumati. Ruyatan Limustaqbal Alkhitab Alearabii Althaqafii, Alkuayt. Almajlis Alwatanii Lilthaqafat Waladab: Silsilat Ealam Almaerifati, E265 .

\section{REFERENCE LIST}

Bagely, Carole, And Hunter, Barbara. (1992). Restructure, Constructivism and Technology, Educational Technology, Vol.33,No5,pp31-37.

Gary G. Bitter, Melissa E. Pierson. (2007). Using Technology in the Classroom, 2007, P25-46.

Mckenzie, Jamie. (2001). Technology Litracy And Recruitment, The Educational Technology Journal, Vol3,No7, March, 1993, Available at(On-Line):URL=http://www.fno.org/FNOMar93.html, visited in $12 / 7 / 200$.

Terry Thode. (1996). Technology Education and Elementary School, The Technology Teacher, Vol.55, No.6 ,p7. 